Florida International University FIU Digital Commons

4-28-2001

\title{
Architecture as friendly interface a digital information facility for the village of Islamorada
}

Linda Feinberg

Florida International University

DOI: $10.25148 /$ etd.FI15101357

Follow this and additional works at: https://digitalcommons.fiu.edu/etd

Part of the Architecture Commons

\section{Recommended Citation}

Feinberg, Linda, "Architecture as friendly interface a digital information facility for the village of Islamorada" (2001). FIU Electronic Theses and Dissertations. 3230.

https://digitalcommons.fiu.edu/etd/3230

This work is brought to you for free and open access by the University Graduate School at FIU Digital Commons. It has been accepted for inclusion in FIU Electronic Theses and Dissertations by an authorized administrator of FIU Digital Commons. For more information, please contact dcc@fiu.edu. 
FLORIDA INTERNATIONAL UNIVERSITY

Miami, Florida

ARCHITECTURE AS FRIENDLY INTERFACE

A DIGITAL INFORMATION FACILITY FOR THE VILLAGE OF ISLAMORADA

\author{
A thesis submitted in partial fulfillment of the \\ requirements for the degree of \\ MASTER OF ARCHITECTURE
}

by

Linda Feinberg 
This thesis, written by Linda Feinberg, and entitled Architecture as Friendly Interface: A Digital Information Facility for the Village of Islamorada, having been approved in respect to style and intellectual content, is referred to you for judgment.

We have read this thesis and recommend that it be approved.

Patrice Gerard

Date of Defense: April 28, 2001

The thesis of Linda Feinberg is approved.

Dean William McMinn

School of Archit

Dean Douglas Wartzok Division of Graduate Studies 
- Copyright 2001 by Linda Feinberg

All rights reserved. 
DEDICATION

I dedicate the accomplishment of this thesis to my father. Although we have not always been on the same page, you have always unconditionally provided me with the positive support to pursue my dreams. It feels so good to say "I did it!"... and I could not have done it without your absolute love and advocacy. Thanks for everything dad.

I love you. 


\section{ACKNOWLEDGEMENTS}

I thank my three thesis advisors for generously offering their time, patience, enthusiasm and invaluable feedback through the progression of this thesis. Thank you Professor Gray Read for your constant zest, devotion, and on-hand avail. ability as Major Professor. I also greatly appreciate the advice you enriched me with through this process.

Thank you Professor Claudia Busch for accepting this thesis appointment during such a demanding time in your life. You have positively cultivated my education since my early days in architecture and I was greattul you were on my team. The open-mind and clarity you bring to teaching has undoubtedly assisted me in my educational progress.

Thank you Dr. Patrice Gerard for volunteering your knowledge, excitement and time towards this thesis. I appreciate your ability to understand and become engrossed in a field other than your own. Thanks again for those last time . consuming moments of

painstaking editing.

I would also like to take this opportunity to thank others in my life who mean so much to me. Much appreciation goes to my mother, who would drop everything for my needs. I am indebted to you for the home-cooked food and those last minute trips to the library. You're a working woman's rote model. Thanks and I love you.

Some people don't even have one mother, yet I have been fortunately granted with two. Special thanks Gilda for providing me with that extra dose of unconditional love. You're always there for me and I couldn't ask for anything more. I would like to list those teachers who have profoundly influenced my passion for design

Mrs. Tobe (High School Art Teacher)

Mr. Gambill (High School Art Teacher)

Lee Dejasu (RISD Freshman Foundation)

Victor Lara (RISD Freshman Foundation)

George Scott (RISD Industrial Design)

Armin Hoffmann (Yale University)

Dorthea Hoffmann (Yale University)

Doug Scolt (RISD Graphic Design)

Claudia Busch (FIU Architecture)

Rene Gonzalez (FIU Architecture)

Special thanks to Danny for those extremely helpful moments just hours before the thesis defense. Finally thanks to Jessica, Kalliopi, Danny, Ricky, Julie and Sophie, who have stuck with me through the good times and the grooling times. 
ABSTRACT OF THE THESIS

ARCHITECTURE AS FRIENDLY INTERFACE:

A DIGITAL INFORMATION FACILITY FOR THE VILLAGE OF ISLAMORADA

Linda Feinberg

Florida International University, 2001

Miami, Florida

Professor Gray Read, Major Professor

As the objects of technology advance, today's ubiquitous computers may soon vacate our desktops to inhabit society as cultural artifacts. This thesis explores individual's relationships with current communication technologies. The consideration of scale in future information systems opens the door to opportunities for improvement. Architecture becomes the medium to relieve the issues of misinformation in Islamorada, Florida.

Future communication systems as conceptualized by the Cranbrook Academy of Art Industrial Design students, as well as similar systerns implemented by M.I.T. Media Lab students, were reviewed. Retrieving information will no longer be limited to the remote access of a computer. Information accessing will now involve interaction at an environmental scale through the medium of walls, ceilings, furniture, etc. The examination of the Islamorada context reveals the challenge to design a progressive information facility, where island residents do not sense invasion by modern technology.

The Information Facility that I am proposing for the Village of Islamorada can best be characterized as an interface where relationships are mediated between the individual and the invisible information world. By recognizing opportunities within the concept of interface, a media center emerges, providing Islamorada residents non-intimidating access to the advanced world of digital information 
TABLE OF CONTENTS

CHAPTER

II CRANBROOK ACADEMY OF ART: $1987 \cdot 1994$
2.0 Reassessing Product Form
2.1 Pager by Leif Huff, 1993-1994
Interactive Projection Computer by Masamichi Udagawa, 1989.1990
Forest of Information by Robert Rabinovitz, 1991-1992

A Redetinition of Form

III MIT MEDIA LABORATORY

3.0 Implementing the Future

3.1 An Installation of Interactive Furniture, 2000

3.2 Laser Wall, 2000

3.3. The Magic Carpet, 1999

3.4 Communication Technology and the Environment

IV A PORTRAIT OF ISLAMORADA

4.0 A Village of Misinformation

4.1 Is lamorada: Center of the Keys

4.2 Islamorada: Lack of Growth

4.3 Is lamorada: Resources

4.4 Routes

4.5 Founders Park

4.6 Conclusions: the Solution is a Program

$\checkmark$ CONCEPTUAL FRAMEWORK FOR AN ACCESSIBLE CENTER

5.0 Ergonomics and Intormation Access

5.1 Measuring Human Interaction

Suríaces and Wall Spaces

Vernacular: Lighthouses, Antennas and Billboard

Sun in Context

Scale in Context

Interface is Redefined

ARCHITECTURE IS DESIGNED AS INTERFACE

6.0 A Digital Information Facility for Islamorada

6.1 Interface for the Vernacular: structure \& organization

6.2 Interface for Natural Resources: position \& skin

6.3 Interface for Mind and Body: media walls

64 Interface and the Development of a Plan

Beyond Mediation 


\section{FIGURE}

2b. Pager viewed as a broach, (C) Leif Huff 1994.

2c. Pager viewed as a pocket watch, (C) Leif Huff 1994.

2d. Interaction Projection Computer by Masamichi Udagawa, (C) Masamichi Udagawa 1989.

2e. Interaction Projection Computer detail, @ Masamichi Udagawa 1989.

2f. Forest of Information Computer by Robert Rabinovitz, @ Robert Rabinovitz 1992.

28. Forest of Information hand detail, @ Robert Rabinovitz 1992.

3a. An installation of Interactive Furniture, (-) the MIT Physics Media Group 1999.

3b. Interactive Furniture sectional drawing of mechanics, @ the MIT Physics Media Group 1999

3c. Interactive table detail; video clip, (-) the MIT Physics Media Group 1999.

3d. Laser Wall; diagram, ( ) the MIT Responsive Environments Group

3e. Laser Wall; video clip, () the MIT Responsive Environments Group

3. Magic Carpet; diagram, $\odot$ the MIT Responsive Environments Group

3g. Magic Carpet; video clip, (-) the MIT Responsive Environments Group

4a. Selected articles demonstrate Islamorada angst, courtesy of The Reporter Newspaper

4b. Location of Islamorada diagram, (C) Linda Feinberg

4c. Franchises in reference to Islamorada; diagram, ( ) Linda Feinberg

4d. The Reporter Newspaper Building, Linda Feinberg

4e. Islamorada resources diagram, (C Linda Feinberg

4f. Travel in Islamorada diagram, $\odot$ Linda Feinberg

4g. Founders Park diagram, $\odot$ Linda Feinberg

4h. Founder's Park topographical aerial; photo, courtesy of Terraserver.com

4i. Founder's Park orthogonal aerial; photo, courtesy of Plantation Yacht Harbor Marina
FIGURE

PAGE

4j. Nova Southeastern Technology Plan; Table of Contents, @ Nova Southeastern University 19

5a. Activity area of Founder's Park; sketch, $(-$ Linda Feinberg

5b. Human interaction with a chalkboard; video clips, $\odot$ Linda Feinberg 20

5c. Chalkboard demonstration; photo, Linda Feinberg

50. Overlapping layers from chalkboard analysis; diagram, @ Linda Feinberg 21

5e. Space of personal interaction; photo, Linda Feinberg 21

5f. Human mark recordings; plaster molds, $\odot$ Linda Feinberg 21

5g. Wall of measured interaction; collage, ( Linda Feinberg 22

5h. Surface study; plaster model, $\odot$ Linda Feinberg 23

5i. Interior wall construction; photo, courtesy of Yale University's British Art Center 23

5j. Wall study; basswood model, @ Linda Feinberg 23

5k. Wall study; basswood model, @ Linda Feinberg 23

51. Lighthouse section over carekeepers diary, courtesy of Pineapple Press \& the Monroe County Public Library 24

5m. Illuminating tower; collage, $\odot$ Linda Feinberg 24

5n. Islamorada antennae; photo, Linda Feinberg 24

50. Conceptual walls; sketches, (ㄴ) Linda Feinberg 24

5p. Experience concepts; collage, $\odot$ Linda Feinberg 24

5q. Projection square in Munich, courtesy of M. Holberton 24

5r. Islamorada billboard; photo, Linda Feinberg 24

5s. Location for Information Center; diagram, @ Linda Feinberg 25

5t. Stereographic diagrams, produced using Square One software 25

5u. Shading diagrams, produced using Square One software 25

5v1. Immediate environment scale diagram, (- Linda Feinberg 26 
5x2. Abstracted variables of the community; diagram, 0 Linda Feinberg

6s. Second floor plan (rental space); drawing, @ Linda Feinberg

6e. Northeast elevation view; model, ( ) Linda Feinberg

6v1. Solar panel detail; model, ( ) Linda Feinberg

6t. Structural detail; sketch, @ Linda Feinberg

6v2. Satelitite level circulation; sketch, ( L Linda Feinberg

6g. Site plan of Founders Park; model, ( $)$ Linda Feinberg

6.3. Radio Mast; photo, courtesy of ORF studios, Austria

6g1. Site plan detail, model, ( ) Linda Feinberg

'not labeled' Islamorada Digital Information Facility; collage, $\bigcirc$ Linda Feinberg 


\section{INTRODUCTION}

Advances in computer technology and communications have led to dramatic increases in information that is available to people. However, the interfaces used to access this data are awkward. Consider the conventional computer setup. A mouse, keyboard and monitor connect to a mystery box, which contains hardware foreign to most of it's users. These interfaces are not intuitive. They are new languages to be learned. The experience is not simple and therefore, not pleasing. The computer's use of space is obstructive to one's surroundings. Sitting in front of a remote computer often means ignoring one's surrounding environment. In the last thirty years, the visual language of these objects has also become limiting through it's ubiquitous 'black-box' aesthetic. People have become foreign to the nature of technology. Spawned by mass production, current communication technology promotes dehumanized relationships. Human experience is warming up the cold precision of technology to make it livable, and lived in. Does technology serve the user or is the user a slave to the mass-marketing of hightechnology?

The beginning of this thesis provides research concerning the Industriał Design Projects developed at the Cranbrook Academy of Art of Bloomfield Hills, Michigan. The study of projects focuses between the years of 1987 and 1994, during a time of radical departure from the accepted design vernacular. The experiments within the Cranbrook Design Department recognized the limitations of conventional design, which society had formerly accepted without question. Conclusions present a variety of different relationships that are taken for granted between the technological object and the individual user.

The third chapter focuses on the implementation of these "new" concepts by students of the MIT Media Lab. Three specific projects suggest a concern to improve the current state of dehumanization with technology. Examination also concludes a link between computer design and architecture. In particular, the integration of environments in communication design could lead to the development of more ergonomic interactions between human beings and technology.

In chapter four, a specific direction is examined as a means of developing a humanized system of information accessing. The unique environment of Islamorada is discussed with emphasis on the paradox of a traditional island community connected to 21 st century communications technology. Analysis of the village context and issues demon. strates a distinct character portrait. The need for a friendly information facility emerges.

In chapter five, the reiationship between the unique geographical location of Islamorada and the need for an advanced information system is delineated. The measurement of human interaction within a designated site is attempted. The importance of several environmental variables, such as scale as an essential design consideration, are discussed in the articulation of an ergonomic facility for Islamorada. The term interface is coined to describe the proposed 'Digital Information Facility.'

The thesis concludes with the presentation of the 'Digital Information Facility.' Specifics and details concerning the Facility and it's architecture are provided. The underlying premise of this study manifests the proposed environment as an interface to ease the accessing of information for the residents of Islamorada. Thus, the principals of context within the field of Architecture and the principals of human interaction within Product Design, have been fused together to form a friendly and accessible high-tech information center. 
II

\section{CRANBROOK ACADEMY OF ART 1987-1994}

\subsection{Reassessing Product Form}

In the Fall of 1991, the Cranbrook Academy of Art in Bloomfield Hills, Michigan, sponsored an exhibition which displayed the student work of the Academy's Design Department. The catalogue of this exhibit, entitled Cranbrook Design: the New Discourse, revealed that the experiments conducted within the school, from 1987.1994, were of extraor. dinary significance to the national design community. This chapter focuses on the Industrial design projects repre. sented and the innovative concepts which were later realized. Several Cranbrook design projects are examined as a vehicle to understanding the different types of forms, relationships and spaces that can be developed between objects of high technology and the human condition.

Through the 1980's, students in the Design Department were encouraged to read contemporary philosophy and apply their individual findings to their design process. Customized reading lists in philosophy led students to question the value of design and the success of conventional languages of design in society. Examination of theses during the years of 1987 to 1994 , revealed that student's projects varied greatly from other design curriculums. Viewed as a whole, the majority of these three-dimensional design experiments were all consciously reacting to conventional images and forms of technology and their association to America's culture of industrial consumption. New definitions of the object's form and function in relation to the human, were generated from these intensive readings in philosophy. The result of these experiments highlighted the limitations of current design which society had formerly accepted without question.

In the early 1980's, the visual and formal vocabulary of product design and architecture was limited to simple geometrically described lines, planes and abstracted solids. This design aesthetic was associated with the development of Modernism. ${ }^{2}$ Coinciding with the Industrial Revolution, Modernism's 'Universal Design' appeal sought to develop an international language of product form compatible with technology. The global nature of technology strove to form components, which universally work together in various combinations and environments. Most of the industrial designers of this time, from the beginning of the 20th century, attended to designing the function of an object. The beauty of an object was only seen as a result of its functional solution, not necessarily it's formal aesthetic. In the 1960 's, Modernist ideas flooded American corporate environments. ${ }^{3}$ At this time the need emerged for a systematic, corporate language of product form. Trained in rational design methodologies, designers concentrated on ergonomics, business strategies and the development of an approved, universal industrial language. Companies like Braun and IBM used the abstracted aesthetic to tame the influx of objects crowding environments. For example, appliances and their forms were simplified and generalized so they all could reside together aesthetically in a home.

Following the many years of Modernism influences, the Design Department at Cranbrook became interested in the philosophical perspectives that questioned whether the limited universal language was adequate to the task of inter. preting technology to the user. By the middle of the 1980 s, experiments within the Cranbrook Design Department consciously began to examine the nature of these questions. Dialogues emerged toward a desire to understand the designer's responsibility in a culture dependent upon objects. What resulted was a theoretical shift from universally legible design systems, to communicating design through the meaning and form of a product.

Many of the design experiments at Cranbrook during this time began to switch from the Modernist notion of function from the gearbox of the object. to the service being performed. The servicing of the object signified the inter. action with the user. The forms found in student projects were no longer dependent on the former ubiquitous black boxes such as in the design of contemporary microwaves and televisions. New definitions of what an object should communicate were created.

Many discourses, like the one established in the 1985 exhibition 'Les Immateriaux,' curated by French philoso. pher Francois Lyotard, emphasized the ever-greater degree to which people found it difficult to relate to current technology. He argued that "...far from alienating people, the complex workings of the latest gadgets, can free them from former cares. Where understanding how to operate a product was once the priority, there is now the scope, instead, to develop a feeling for it. ". Contemporary dialogues, such as Lyotard's, had a profound effect on those at the Cranbrook Academy of Art. In 1989, Michael McCoy, resident artist of the Cranbrook Design Department stated "....ur cherished objects have a presence, which we intuitively understand to contain sub-layers, although the precise or full meaning may not be accessible. It is the realm of the implied, the poetic." "' 
Several Cranbrcck projects, which were influenced by such philosophies, are discussed in the following pages. As the reader will note, the solutions not only broke out of the 'black boxes,' in the redefinition of form, but emphasized the space between the object and the user as a form within itself. This in-between space was recognized as a form where human interaction occurs. The later chapters of this thesis focus on these intangible spaces of human interaction.

The three thesis projects discusses in the following pages are representative of approximately thirty very different projects completed during 1987.1994 at the Cranbrook Academy Department of Design. The projects were selected by the amount and clarity of information germane to this study. In each of the experiments examined, the object, it's form and it's relationship to our human condition is noted.

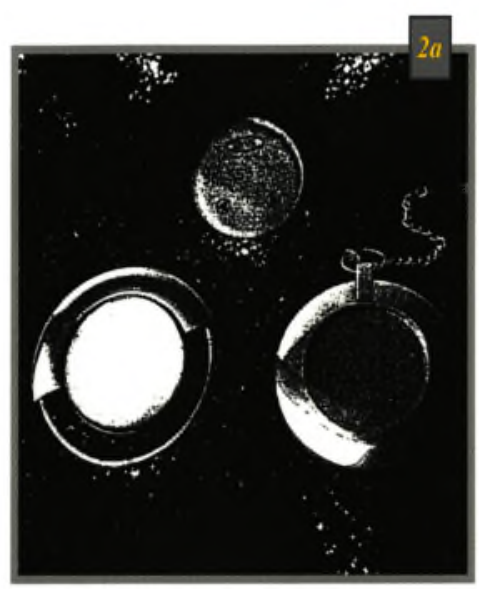

\subsection{Pager by Leif Huff, 1993-1994}

In an effort to describe the problems of the machine today, Leif Huff quoted cultural critic, Ben Nicholson, in his 1994 thesis. ${ }^{8}$ From Nicholson's 1990 Appliance House, Huff noted that the problem of technology lies in a dislocation between electronic form and the human mind. The inner workings of the today's machine are foreign and overwhelming to the user. "[Users] dare not remove the panel to inspect the [machine's] innards for fear of being struck down by the voodoo wisdom held over the appliance by the manufacturer. Because the manufacturer and mechanic retain the secret rites of the appliances, the uninitiated owner will always use the device out of harmony with what drives the activity from the underside of the panel. The comprehension of methods of repair are thus separated by the opacity of the sheet of steel and plastic: the methods are incongruous, leading to a tearing of the two ways of thinking about an appliance which in turn leads to separation of the senses." 9

Cultural critic, Claudia Dona's was also quoted in Huff's thesis for her 1988 discussion pertaining to opportunities involving the current object/human relationship. "After centuries of building objects as projections of our bodies, we can now begin to consider them as projections of our minds." ${ }^{10}$ From these readings, Huff questioned the role that function plays in the high-tech object. Huff asked questions such as "what if the controls of the functions of machines shrink down to the sole interface of a screen, with use of a little pen-like pointing device?" "Or what if the form of a product could disappear completely? ${ }^{11}$ He believed redesigning the function of a product would reaffirm the power of the subject, by

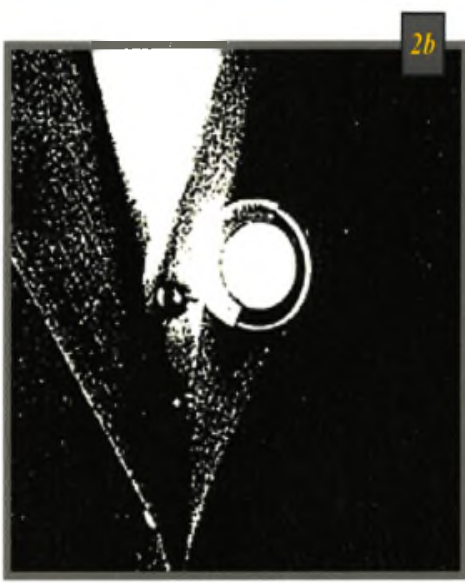

highly personalizing the object. His ultimate goal was to create objects that are intimate to the human, not alien. He theorized that objects should have more powerful relationships with humans, which requires more than the current visual treatment of today's ubiquitous electronics. "Our individual conscious. ness becomes more and more rich in pictures but also lacks a certain window or a contact. ${ }^{\text {n12 }}$ He believed the visual quality of current tech-objects ignores the use of the other human senses

Huff's design of a phone pager exemplifies the apparent need for intimacy in design. (figure 2a) A metaphorical form

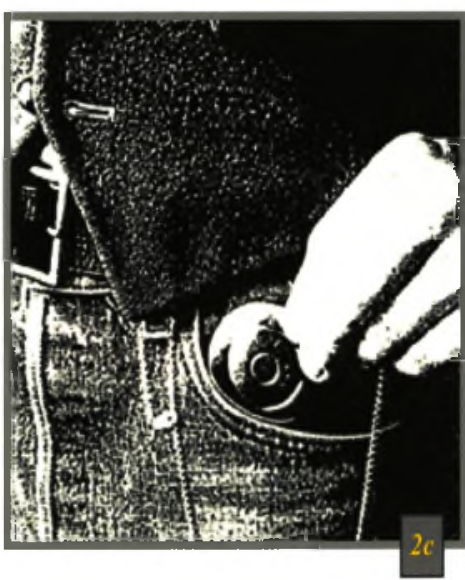
of jewelry is referenced, in order to define what a pager should physically and mentally symbolize to its owner. Out of aluminum, brass, copper and plastic, the pager becomes an ornamental accessory to the body, like a pocket watch, a brooch or a necklace. He designed the pager with inter.change. able properties so the user has the ability to define the pager's placement on his/her body, as different pieces of jewelry. (Figures $2 b \& 2 c$ ) Once the pager is signaled for a message, phone numbers are retrieved from its touch-interface circular screen, located on one side of the object.

The application of the jewelry model to the form of an electronic pager is a powerful declaration. One must ask how jewelry relates to the body. Webster's defines jewelry as "...objects made of precious materials and worn for personal adornment..$^{13}$ Jewelry is generally small in scale in relation to the human body and usually carries more value than it's 
fiscal worth. Jewelry can also evoke memory, emotion and sentiment. Huff's pager suggests that technology does not have to be cold and devoid of personal meaning. The small scale, detailed form and material of the pager make it desirable. Therefore, the object has been given another function. The pager not only communicates through signals, but also through sentiment, By the imposition of jewelry as a metaphor, is this pager considered a physical gadget or a sentimental object? it it tails to function as a pager in time, or more improved pager. like products develop, does one throw the pager away - or does it get added to the shoebox of memories in the closet? Does the pager in fact become an emotional object to us by it's metaphorical form? Or on the other hand, does the emotiona form of jewelry become a physical, meaningless gadget?

The fact that the user can define what form of jewelry the pager becomes, adds significant underpinnings to its relation ship with the body. Huff consciously gave the user the oppor tunity to define the role of the object with the booy. The form of jewelry is also more temporal to our bodies than perhaps a tattoo, or a piercing hole. These objects are chained to our bodies in some form such as a necklace, a brooch or a watch Huff's project proposed a pager that could be voluntarily linked to one's body, almost as an extension of it. He was possibly exemplitying how frequently pagers are used and dependec upon by people in society. We often carry our sentiments around with us by wearing jewelry and carrying other meaningiul things, such as good luck tokens. Huff's pager also suggests that people add signals and phone number messages to the mental luggage our body and mind already carry. The space between the pager and the user's body dissolves as sentiment develops with the object.
2.2 Interactive Projection Computer by Masamichi Udagawa, 1989-1990

Philosopher, Paul Virilio, was referenced in Masamichi Udagawa's thesis of $19900^{14}$ Virilio, in his 1977 book, Speed and Politics, explained how society is in need of a new science, one which considers another view of objects and surfaces in relation to the body and culture. This science, teletopology, ${ }_{1}^{15}$ examines not only surfaces, but interfaces as well. Virilio's definition of interface was "...the organization of space which depends not simply on the means of construction but on the means of communication it is to house."16 Influenced by this philosophy, Udagawa meticulously articulated the interface between the human and the invisible information world in his Interactive Projection Computer. (Figure 2d) Focusing on the experience of an object in the design process, more than the form of the object, recovers a natural physicality once lost by the indirect experienced objects currently existing within society. Udagawa's computer is more about the event of navigating through the information environment than the form, which the object carries. He stressed the interface between man and the environment, and suggested that navigation through information worlds, such as the internet, should not be foreign and inhibiting.

The Interactive Projection Computer's form initially consisted of a projector, camera, voice recognizer and external pen.

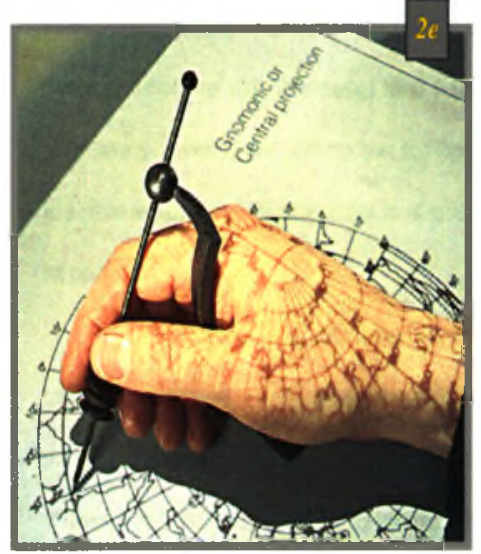

pointer. Visual information is projected on to the surface of a desk. The desk becomes the computer screen. Touching and pointing on familiar icons projected on to a desk surface is one method of interaction with this computer. (Figure 2e) For example, in order to make a phone call, one would touch the visual symbol of a telephone projected on the desk. The camera recognizes the human movements and signals the information back to the computer brain to process. Once the telephone is touched, it is magnified on the desk and one can then further the phone call by touching its numerical buttons, simulating the familiar event of using a telephone. 'Talking' to the computer is also an option in the interaction between the user and this machine. The foreign systems inside today's computers are usually assigned to engineers for development. However, Udagawa's computer exists as a reaction to today's computer processing systems, which "...still require linear input and 
indirect data manipulation." ${ }^{17}$ He developed a new processing system, where the information is gathered, stored and projected in a mosaic format. This format was used to develop the computer language because, according to Udagawa, this system identifies with "...peoples natural way of non-linear, mosaic like thinking." He felt that this would facilitate the event of interaction between the individual user and the computer.

The vertical form and projection head of the computer symbolizes a floor lamp. As a lamp projects light outward, the computer also projects it's information outward, onto another element such as a desk surface or the surface of a wall. Consider the traditional concept of moving back to working upon a desk. The desk's history within the furniture world, it's usage, and the emotional response to the touch and smell of it's material, references the meanings behind objects from the British Arts and Crafts Movement at the end of the 19th century. ${ }^{19}$ Relocating the computer screen to the surface of the desk frees information from the former limited square frame of the computer monitor and provides for a more flexible, familiar and comfortable working environment for the individual.

Udagawa viewed his proposed technology as an improvement to the cold and dehumanizing interactions stimulated by today's computer systems. The computer object remains in the background, while the intangible space between the object and the user became the focus. This space, along with the computer object, it's inner system, the desk, the projection light and the projection itself, becomes another meaningful component, another form, in the use of Udagawa's revolu tionary computer.
2.3 Forest of Information by Robert Rabinovit, 1991-1992

The central focus of Robert Rabinovitz work was the study of Phenomenology. He quoted the Phenomenologist, David Michael Levin from his 1985 book, The Bodies Recollection of Being. "We are moving closer to being well-balanced

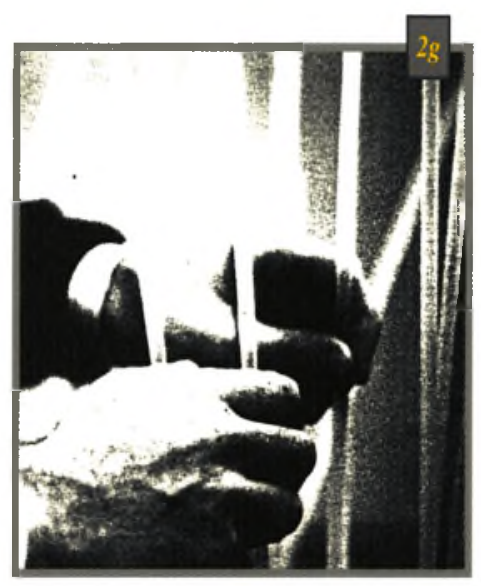

when our standing is thoughtfully centered on the grounding provided by the earth. We are moving closer to being wellbalanced when the standing of our being in relation to the presencing of being is deeply understood through our embodi. ment and our standing has attuned the posture of our standing to that field of wholeness on which it rests." Throughout Rabinovitz's thesis, he stressed the importance of understanding the human beings location amidst a world that preexists us. The experience of being grounded on earth is only what one knows. According to Rabinovitz and like Phenomenologists, our understanding of being is only understood in how we, our bodies and minds, relate to the world. "When our encounter with other beings takes place in a situation where we are not well.centered and well.balanced, we will naturally be preoccupied with our own eco.logical security, our own standing. However, when we can encounter beings in a more relaxed condition, it is easier to release them from the structural field constituted by our anxiety: we begin to let beings be."23

The development of forms, which can contribute to a conscious awareness of the human condition and explore possi. bilities in the realm of human relationships, influenced Rabinovitz's experiments at Cranbrook. Investigations concerning the location and stability of the body in space were significant to his projects. For example, in his prototype for The Forest of Iniormation (Figure 2f), Rabinovitz formulated a landscape of digital information relative to the human mind and body. He designed an information system as an event within an environment. The landscape of a forest was used as a metaphor for the poetic discovering of information, rather than the notion of accessing of information. He relates his Forest of Information as "...getting off the elevator on the fourth floor and walking around, looking at what is on the floor, then getting back in the elevator to look at another floor.." ${ }^{24}$ The project consists of fiber optic poles, which are vertically planted into 
the ground. The overgrown, grass-like poles carry image, text, sound, scent and light from the ground power source of networked circuits. The user runs fingers up and down these rods to discover the information. Squeezing the rods accesses further detailed information. The information gathered is projected onto walls, floors or the ceiling surrounding the landscape. (Flgure 2g)

The random placement of the poles was foreseen to create a series of unexpected relationships between the human and media, between the human and the ground and between human and human. Discovery occurs when unrelated information is brought together by the random access of these rods. Rabinovitz's computer also encourages relationships between people and the earth when one interacts with the fiber rods, which are physically and electrically in-touch with the ground below. Rabinovitz believed that less mechanical relationships develop when people are pulled out of their secluded workspaces. He designed this landscape so many people could access information simultaneously, in a social setting.

Another poetic relationship develops between the human and the environment. Rabinovitz used the forest landscape as a metaphor because he believed this model environment is closer to the reality of our natural interactions, as opposed to the indirect interactions generated with a conventional computer system. The scale of the project was defined in terms of a landscape. The projection of information occupies the surfaces of the surrounding environment. Rabinovitz's fused the multi-dimensional boundaries between object, light, space, event and being into his computer system. As the computer consumes the environment, it encompasses and embodies the surrounding architecture. The environment and the computer are one.

It does appear that navigating through Rabinovitz's information environment would engage the human in a plurality of ways. However, his concept stimulates further questions. For example, what sounds do the interactions make? How do the fiber weeds feel on one's skin? These unexplained interactions should be considered when evaluating the experiment.

\subsection{A Redefinition of Form}

This chapter explores the Cranbrook projects and the progressive forms that developed. Each student project from Cranbrook during this period of study, 1987-1994, considered different spaces and relationships between the project forms and the human condition. Some projects attempted to define that space, some projects ignored that space and some projects destroyed that space. After close examination, the designed objects are physically becoming smaller or are deconstructed into smaller elements of a greater whole. The space between the object form and human is no longer ambiguous but consciously considered in the design process. Essentially, these projects redefine the preconceived notion of form. Intangible forms of interaction are considered to have the same design significance as the physical form of an object. The service and event of using a computer becomes just as meaningiul as what the computer looks like.

The other thirty Cranbrook projects not represented in this study also stressed spatial configurations between the high-tech object and the human. All of these projects uniformly recognized the current problem within the language of technology. The experiments demonstrate that technology no longer needs to be cold and alienating to the human condition. In 1989, Cranbrook Professor Michael McCoy stated ".... What needs to be articulated, regardless of the format of the man-machine relationship, is the goal of humanism through machines." to cultivate McCoy's notion. 


\section{Notes}

1. Under the Cranbrook Curriculum, philosophies such as Semantics, Structuralism, Post-Structuralism and Phenomenology were mined by the Industrial Design students. Information pertaining to the significance and influence of the theory may be found in a prethesis research paper. Linda Feinberg, "Design Projects at the Cranbrook Academy of Art from 1987.1994 (During the McCoy Curriculum): An Analysis of the Interspaces Between Objects of Technology and the Human" (Pre-thesis Preparation Class, Florida International University, Miami, December 2000), 13.26.

2. Modernism was a movement parallel with the inception of the Industrial Design Revolution, which released the languages of design form from the responsibility of their authors. The goal behind Modernism was to create a universal language in design.

3. Victor Margolin, et al. "Closing Essay" in Design Discourse, (Chicago: University of Chicago Press, 1989),

4. Feinberg, "Design Projects at Cranbrook," 22.

5. The 1985 "Les immateriaux" exhibition at the Centre Georges Pompidou in Paris was one of the first shows to explore the intersection of information technology, art, industry and culture. The exhibit was curated by philosopher Jean. Francois Lyotard.

6. Lyotard, Les Immateriaux quoted in Hugh Aldersey-Williams, ed, Cranbrook Design: The New Discourse (New York: Rizzoli, 1990), 22.

7. Michael McCoy, "The Post-Industrial Designer" (Proceedings from the Product Semantics ' 89 Conference in Helsinki, Finland, May 16 . 19 1989), University of Industrial Arts, Helsinki, e1.

8. Leif Huff, "Form Follows Function... and then what?" (Thesis, Special Collections, Cranbrook Acadenty of Art Library, 1994).

9. Huff, "Form Follows Function," 2, quoting Ben Nicholson, Appliance House (Cambridge, Ma: MIT Press, 1990).

10. Ibid. " 3, quoting Claudia Dona, essay entitled "Invisible Design" in Design Atter Modernism: beyond the object (New York: Thames and Hudson, 1988)

11. Ibid, 4.

12 lbid.

13. New Websters Dictionary and Thesaurus (Danbury, Ct: Lexicon Publications, Inc. 1993).

14. Masamichi Udagawa, "Untitled thesis," (Thesis, Special Collections, Cranbrook Academy of Art Library, 1990).

15. Paul Virilio, Speed and Politics: an essay on dromology (New York: Columbia University, 1986) quoted in Masamichi Udagawa, 'Untitled thesis,' 1 .

16. Ibid

17. Udagawa, "thesis," 2

18. Ibid.

19. The Cranbrook Academy of Art developed from the indirect infiuence of the British Arts and Craft Movement at the end of the 19th century. George Booth, a British coppersmith, found the school based on a "permutation of Arts and Crafts principles similar to those of the Bauhaus, which stressed the creation of a community of artist-masters and students. working and growing through interaction on the intimate scale that a small school could provide." Roy Slade is quoted in Katherine McCoy, Design in Michigan interaction on the intimate scale that a small school could ponid

20. At Cranbrook, the philosophy of Phenomenology was used as a discourse to mine student's past experiences, to plunge into the depths of their subconscious in order to understand and use the nature of their personal perceptions. More about Phenomenology depths of their subconscious in order to understand and use the natu
can be researched in Feinberg, "Design Projects at Cranbrook," 23-26.
21. Robert Rabinovitz, "Explorations and Projects in the Human Experience of Sensorial Phenomena" (Thesis, Special Collections, Cranbrook Academy of Art Library, 1992), 11 is quoting David Michael Levin, The Bodies Recollection of Being (Boston: Routledge Kegan Paul, 1985) 274.

22. Ibid.

23. Rabinovitz, "Explorations and Projects...," 28

24. Ibid., 29

25. Michael McCoy, "The Post-Industrial Designer" (Proceedings from the Product Semantics " 89 Conference in Helsinki, Finland, May 16.19 1989), University of Industrial Arts, Helsinki, e6. 


\subsection{Implementing the Future}

Cranbrook is not the only institute that acknowledges problems and proposes solutions toward the de-alienation of technologies. Founder and Director of Boston's MIT Media Laboratory, Philosopher Nicholas Negroponte once said that..

"...all communications media and technologies are poised for redefinition. The Media Lab was set up to collect that proces and lead it."

In 1985, at the time Cranbrook's Department of Design began to question conventional forms of technology, the MIT Media Lab was implemented. Today, the MIT Media Lab is leading a "...growing focus on how bits meet atoms: how electronic information overlaps with the everyday physical world." ${ }^{3}$ Today, engineers and designers join together to work in select focus groups in order to further specific research in advancing the forms of technology and communication. Like the Industrial Design projects at Cranbrook, the results of the Media Lab uniformly reveal a theoretical shift in the way humans interact with our objects of communication.

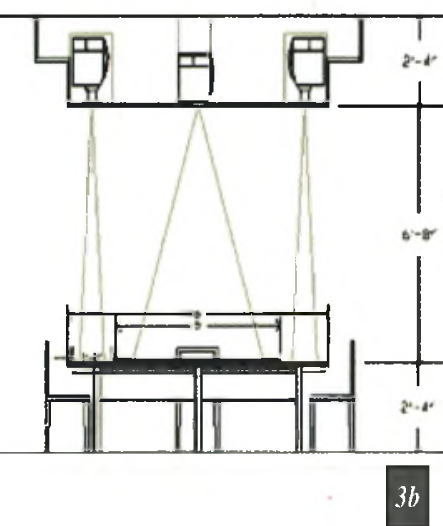
This chapter discusses how computers are evolving from the traditional keyboard-screen-and-mouse machine to computers that are less visible to the naked eye.
Art in New York. The challenge for the group lay in the Museum's desire for an easily accessible computerized display system without compromising the aesthetic appearance of the exhibit. The Unprivate House display was designed to have voice, data, video and image information presented to the visitors within the context of the exhibit itself. $A$ central interactive table was created to spark more social interaction, discussion and movement between visitors and the information they were accessing. (Figure 3a)

The computerized furniture referenced the design of a traditional domestic dining table. Eight place settings on the table featured a display projected from above. In the center of the table was a five-foot lazy Susan holding a set of drink coasters on the outer edge. A different architectural project for the content of the exhibit was also digitally projected onto each one of these coasters. Visually, the circular coasters appeared as colorful buttons or icons to a large computer. However, the coasters could easily be picked up and moved around on a 'placemat' by the visitors. Users could also share their information and images with their neighbors by sending it to be

The computerized hardware for the exhibit became part of the furniture itseff. Projectors within the ceiling, centered above the table, displayed information on the dining table placemats. (Figure 3b) Sensor technology, on the backside of 
the table, recognized hotspots of human movement on the table's flat surface. (Figure 3c) Cameras, also located in the ceiling, sensed the different images within the coasters and sent the information to the hardware built inside the table. The furniture, in this case the table, thus became one large interface for individual and group interaction.

\subsection{Laser Wall, 2000}

While the interactive table for the MOMA exhibit was able to detect and track hand movement, it did not recognize bodily movements on larger surfaces. The Responsive Environments Group ${ }^{6}$ at the MIT Media Lab locuses primarily on interactive surface conditions. Two.dimensional planes such as walls, floors and tables, are explored for media accessibility. At present, interior surfaces generally remain passive, excluding their structural and organizational uses. The Responsive Environments Group's latest projects explore user interlaces within large.scale public settings.

The Group's gestural interiace, better known as the Laser Wall, tracks hand positions with a laser rangefinder. (Figure 3c) A laser beam is scanned over a large sensitive region to detect human movement up to several feet away from its surface. In essence, the Laser Wall is a large touch screen that can track several hands simultaneously. Different media, such as video, text and images, can be accessed from any location and dragged to any other location on a wall. (Figure 3e)
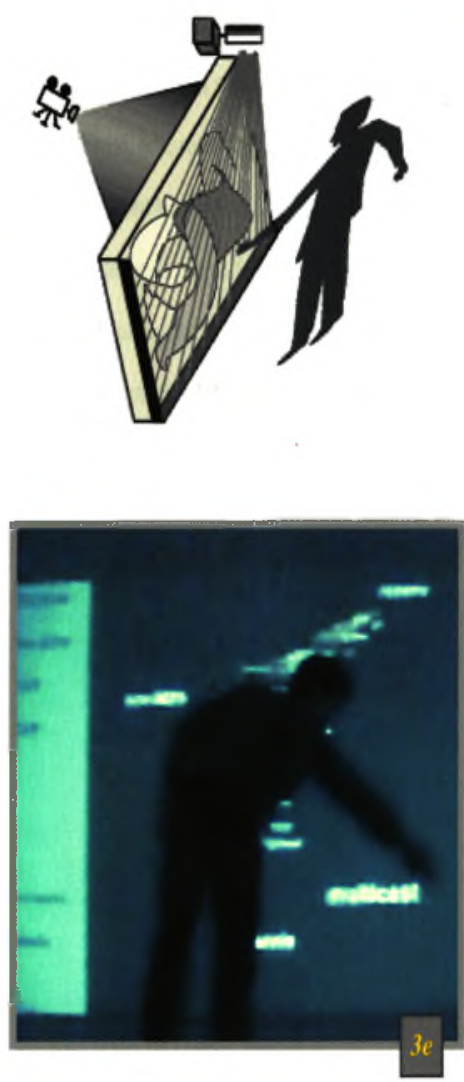

The entire body is used to interact with information across a wall. The wall becomes the computer
3.3 The Magic Carpet, 1999

Walls are not the only environmental skins that the Responsive Environments Group explores for interfaces. Sensored flooring concepts were explored for the Group's Magic Carpet system. 'A grid of protected cable is used for inner insulation in this example of floor carpeting. (Figure 3f) The grid is small and close enough together so the wiring will always lie under the shoe of an occupant. A light layer of plastic protects

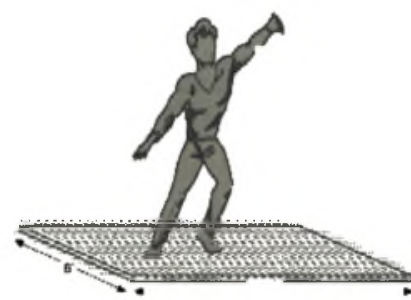
the wires further. When the cables are stepped on, electricity is produced, with amplitude proportional to the intensity of the dynamic foot pressure. The changes in foot pressure are measured and different relative sounds are applied acoustically to the occupied space. When one walks slowly on the carpet, a different noise can be heard than when one would run across the carpet. A group of people jumping will generate a more dramatic sound than if one person jumps. Thus human characteristics, such as weight, speed and style of walk, stimulate individual interactions. (Figure 3g) Not only can the flooring measure foot speeds and pressures with sound, but a radar system inside such textiles can also track body movements.

3.4 Communication Technology and the Environment The implementation of these projects by the students in the MIT Media Lab present a vision for a future world of advanced and integrated information settings. Displays may be immense projections or tiny single-viewer lenses. Input may come from a variety of sensors that detect presence, motion, proximity, temperature change, blood pressure, etc. Most interestingly, the machines themselves are being integrated into the environment. Communication machines are becoming one's furniture, one's walls, one's floors. 
The results of these experiments demonstrate that information is becoming the physical architecture that surrounds us Surfaces within the environment have extraordinary potential for interaction with digital information.

This thesis considers the Cranbrook and MIT Media experiments significant undertakings in humanizing the current forms of communication technology. The research from the Cranbrook Department of Design established that the design of computer objects and their forms are as significant as the design of the services which the objects perform. The Cranbrook design students explored the space of interaction; that space between the computer object and the human condition. "To the vision of its founders, today's [MIT Media] Laboratory continues to focus on the study, invention, and creative use of digital technologies to enhance the ways that people think, express, and communicate ideas, and explore new scientific frontiers." "The actions of both institutions have significantly improved human interactions with machines.

The students of the MIT Media Lab concentrated on how the physical forms of tech-objects could dissolve and become embedded within the environment. Traditionally, the design of communication machines has been left for Engineers and Industrial Designers. However, now the opportunity emerges for the design of computers to intersect with the field of Architecture. The remainder of this thesis explores such an opportunity within the unique environment of Islamorada, Florida.
1. Nicholas Negroponte quoted in Steve Brand, The Media Lab (New York: Viking, 1987), xi.

2. "The MIT Media Laboratory. Information," in the MIT Media Lab website [database on-line] (Cambridge, Ma.: Communications and Sponsor Relations [CASR], 2001, accessed July 12 2001); avalable from http:// www.media.mit.edu/Information; Internet.

3. Ibid

4. The MIT Media Lab's Physics \& Media Group studies "...information content and it's physical representation. These two levels of description are usually considered separately as hardware and software, but many of the most serious challenges and significant opportunities in information technologies lie right at this interface." More about the groups pupose s lound in Physics \& Media Group website [database on.line] (Cambridge, Ma.: Communications and Sponsor Relations [CASR], 2001., accessed July 12 2001); available from http://gn.www.media.mit.edu/physics/purpose.html; internet.

5. Details of "The Unprivate House" exhibition may be found in Olufemi Omojola, E. Rehmi Post, et. al, "An installation of interactive furniture," IBM Systems Jounal V. 39:3\& 4, October 2000 [journal on. line]; available from

http://www.research.lom.com//ournal/si/393/part3/omojola.html; Internet; accessed January 20, 2001

A descriptive video of the table is avaliable on the Internet at hitp://Ww.media.mit.edu/physics/video/momata.

6. Ibid, $861 \cdot 863$

7. The MIT Media Lab's Responsive Environments Group studies “... different kinds of sensing modalities and enabling technologies for smart spaces and infelligent environments, applying them in many research projects that cut across the Media Lab and its sponsor communities. Our work is highlighted in diverse application areas, which range from interactive music systems to smart highways sor communities. Our work is highlighted in diverse application areas, which range from interactive music systems to smart hig and wearable computers." Responsive Environnents Group website [database on-line] (Cambridge, Ma..: Communications and

8. Joseph Paradiso, Kai.yuh Hsiao, et al, "Sensor Systems for Interactive Surfaces," IBM Systems Jounal V. 39:892:914:3 \& 4, October 2000 [journal on.line]; available from http://www.research.ibm.com/journal/sj/393/part3/paradiso.htrnl; Internet; accessed January 20,2001. A descriptive video of the project is available on the Internet from http://www. research.lbm.com//ournal/s//393/part3/paradiso.html

9. Ibid., 904.906

10. Ibid, 903

11. "The MIT Media Laboratory - Overview," in the MIT Media Lab website [database on-Iine] (Cambridge, Ma.: Communications and Sponsor Relations [CASR], 2001. accessed July 16 2001); avallable from http://www.media.mit.edu/Intormation/Overview/internet. 
A PORTRAIT OF ISLAMORADA

\subsection{A Village of Misinformation}

In the spring of 1997 , four islands in the Florida Keys incorporated into one village called Islamorada, "Village of Islands." Most colonies have significant issues to resolve in their new state. Islamorada is no different. Traditional residents of the Keys, termed conchs, co-exist with new residents of Islamorada's four different islands: Plantation Key, Windley Key, Upper Matecumbe Key and Lower Matecumbe Key. All residents now share the unified goal of Islamorada: to reclaim the character of the Florida Keys. Each resident has a different idea of what reclaiming the Keys signifies. Some prefer the Keys to remain in its natural, unplanned state. While others call for what they consider necessary change. There is much disagreement within the Village of Islamorada. Village Council meetings have become hostile environments. The negatively charged atmosphere of the meetings has ultimately led to difficulty in developing solutions for significant Village concerns.

Residents are misinformed about Village issues due to the lack of and/or access to information. Since the Villages inception, many issues of the weekly newspaper has published articles which document these misguided attitudes. (Figure

4a) Objective knowledge about community affairs is crucial to avoiding misinformation and hostility in the Village Council meetings. The need for a resource facility, where locals come to access information is obvious. This thesis accepts the challenge. This chapter examines the current setting of Islarmorada in order to understand the villages unique environment and issues. The information is ultimately used to help find a solution for Islamorada's information access problem.

\subsection{Islamorada, Center of the Keys}

The Florida Keys is a group of islands located immediately south of the Florida peninsula. Hundreds of islands called 'keys' are connected to the Florida mainland by one long string, Route US 1. Traveling along Route 1, Islamorada exists as one point aimost centrally located between two other resourceful points. The mainland of Miami is approximately 70 miles to the north of Islamorada, while the well.traveled island of Key West is approximately 75 miles to its south.
Islamorada, is therefore the center of the Keys. (Figure 4b) People from the mainland (Miami and It's north) and from other parts of the country have chosen to reside in the Keys for several reasons. In Islamorada, many of the residents are attracted to an island life of a quiet, secluded atmosphere as opposed to the hustle and bustle of a chaotic city. Residents of the Keys who have been foreign to such city-life, have in fact become intimidated by the modern-day city and the technology associated with it's growth.

\subsection{Islamorada: Lack of Growth}

Similar to other vagabond environments, advertising along the heavily traveled Route US 1 has become a part of the everyday Key's character. Billboards and businesses compete with views of the natural habitat in the Keys. Chains such as Burger King, McDonalds, Arby's, Shell, Eckerds, Mobil, Publix, Winn Dixie, Kmart and others occupy parcels all along USI. However, as one enters Islamorada from the north, these chain establishments are seldom and unlikely to be recognized. (Figure 4c) For example, the Chevron gas station on Plantation Key is primarily known as 'Kut's Korner.' Layton, immedi. ately south of Islamorada is generally residential. As one exits Islamorada to it's south, Key West and Marathon have also become commercialized by urban franchises and tourism.

The distinct Islamorada identity is by no accident. The villages recently developed 2001 Comprehensive Plan states, "OBJECTIVE 1.3.1: IMPLEMENT LIMITED GROWTH OBJECTIVES AND POLICIES. Islamorada, Vilage of Islands shall adopt Land Development Regulations to implement the goals, objectives and policies of this Comprehensive Plan that limit growth within the Village. These regulations shall provide a process for distributing available annual building permits for residential and non-residential development through build-out in the Year 2020, and shall provide incentives for preserving environmentally sensitive lands, extinguishing development rights and promoting redevelopment of the Village Activity Centers..." Future building development in Islamorada is strictly monitored and usually prohibited in order to maintain island ecology and secure it's peaceful island character. This no growth attitude for Isiamorada residents is envisioned to not only prevent environmental pollution and preserve the quality of islamorada living, but also to maintain Islamorada as a village distinct from the other keys. 


\section{PUI THE BRAKES ON BALDWIN BEFORE HE BREAKS THE VILLAGE}

Thu ba Village Mangerer Charles Raldinin touina to ram throush an sBo-millio ther austem that's all worona for Islamerada?

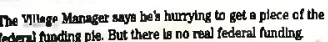

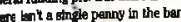

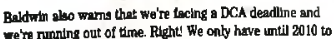

Thet are they gotro to de, 'tanced' 'stamoradar?

an unvone really bellove that the DCA ox any other gov.

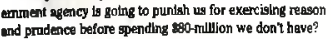
So, whert's the hurry, Charlib?

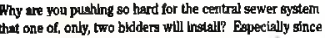

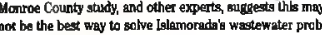
kem? And why are there only two bidde

Chartle' committee says, "For"

Two committees have been stadying thit 1asue- the TER

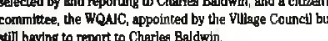

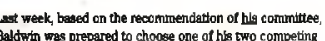

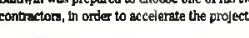

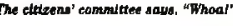

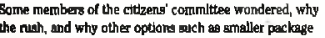
作

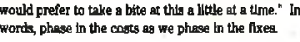
Baldwhin repty, "No comment:

to the Vote?

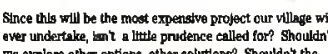

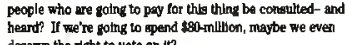

With all this money in the pot, with , we'd be wolse to keep an eve on the dealer.

THERE THINGG EVREY CITUKRN

Get Informed Instat on having the Villinge Councll pres ent all
way.

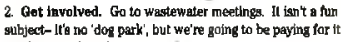

3. Go Into actlon. Wheller or not youtve ever done fit

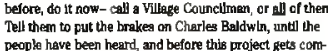
peeple haver been hearc
piserely out of control.

\begin{tabular}{|c|c|c|}
\hline \multicolumn{3}{|c|}{ 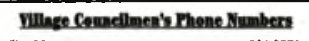 } \\
\hline & & \\
\hline & $\begin{array}{l}\text { Frank Kulishy. } \\
G \text { Gerger }\end{array}$ & 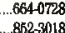 \\
\hline $\begin{array}{l}\text { Mark Cregge } \\
\text { Ron Levy }\end{array}$ & Mark Gregge.... & \\
\hline
\end{tabular}

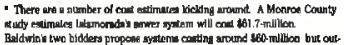

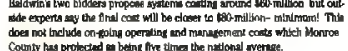

\section{MAD AS HEL}

U N L I M I I E D

No sgenda and wothing to gain but a better ifo.
COUNCIL LOSING CONTRO

For more than two years, I have caken a position of supporing and "give them time" in terms of wating to see wow our new Village of Islands has been run. Earlier, I was most usset in how the Plantatien Yacht Harbor cash businesses by its closing. I've watched the change of command from George Geisler 10 Jim Mooney, still waiting for someone to "walk their tallk."

Today, the council has lost much of its control and actual administration of our village. I don't totally blame [Village Manager] Charles Baldwin for his taking over routines that should be monitored or direcled by the council. Baldwin does have to do his job, even without stork on purchase dollars being capped, without council autho(2) or review. Late apin folks.

Even Charles' performance evaluation has no immediate timetible to be implemented by the council. Jim Mooney is apparently canrying the ball on that matier. This lack of immediacy is unfair to Baldwinn, and
council member seems to care enough to get it done. council member seems 10 care enough lo get it done. been allocated to "complete" needed park upgrades involving utilities, road and repaving changes, tennis cour additions, and various items to allow the park to function as set forth in the improvement plan. Mayor] Frank Kullisky was surrised and dispmointed when several items were no longer part of the bid or contract. The overall job, including these items, would cos more like \$1.6 million

Did someone goof? A poor essimate by the council as to the cost? How come no one outside of Mr. Baldwin or his staff gol to review the final bid?

This lack of control is why the village keeps showing up negatively in my eyes and the eyes of our residen and businesses. We just "blew away" a large sailis group who wanted to use PYH of Founder's Park, called by some. The high fees and some rules which could have bent to a llow 400 or so people to utilize the park and lsiamorada businesses, were not bent to senc

\section{So many bulldozers, so little time}

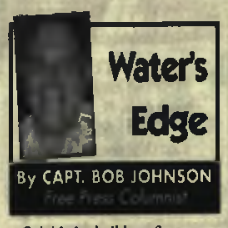

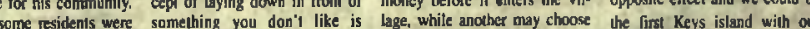

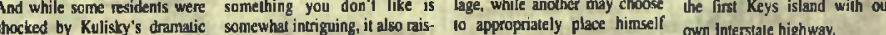
proclamation, others wept. es endless possibililiec, espocial- under our shiny new fire engine. OWevernheless, Frank really

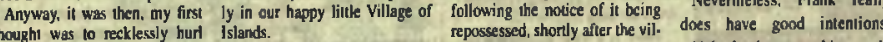

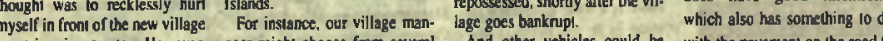

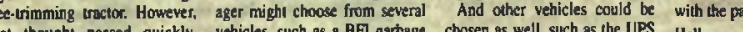

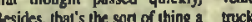

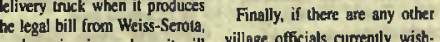
Suicide by bulldozer?

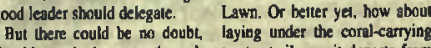
ing to sacrifice themselves for a gested he was willing to end it sacififice, a mass cutbreak of ting crushed by the same valu- officials calches on. it could for a complete amay of options.

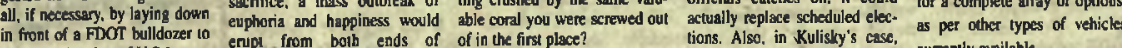

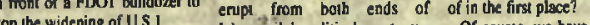

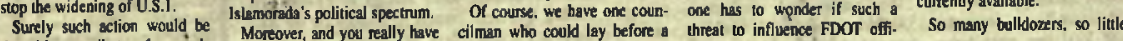

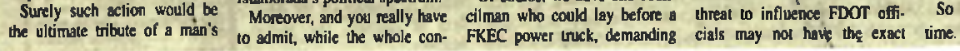

this group, anxious to use our park.. to the park advisory board Yes, seven park board members even voled against this sensibte thenge. These lessons are being leamed at the expense of . rm out of time, and watiting for another election is too in my eyes for changes to atake place. If the counci

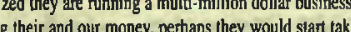
ing charge.

Oh yes, the study group, or seminar recently facilitated by a professional 10 assis our council is getting their jobs

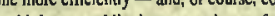
should lower public input - the professional really

The council doesn't lack anything but teamwork. This group of five (in spite of the Sunshine Law) needs to get on the same page, and be a ceara. $M$.

David M. Cohn, Islamorada

HOT TOPC:

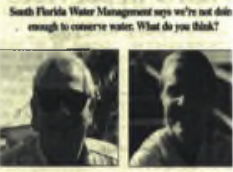

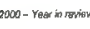

lolamaradu finds same successe

Samereastroursies

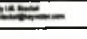

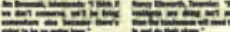

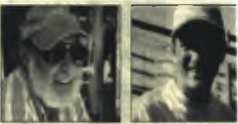

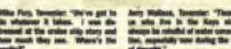
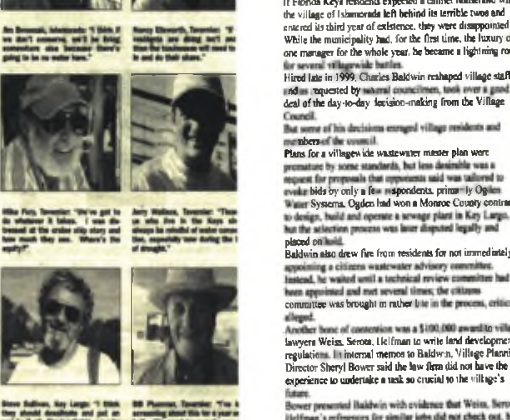

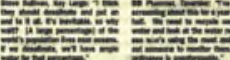

Istamorada moves closer to becoming municipality

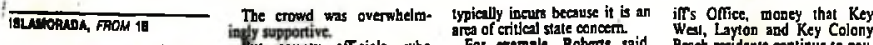

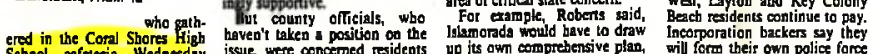

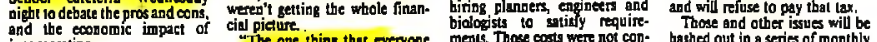

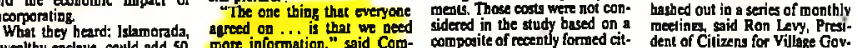

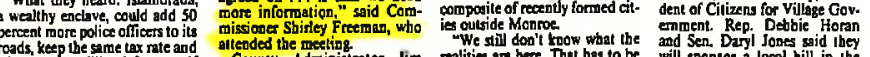

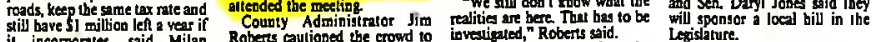

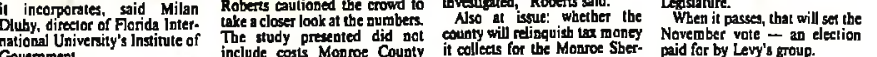

\section{0 years of mismanagement continues still}

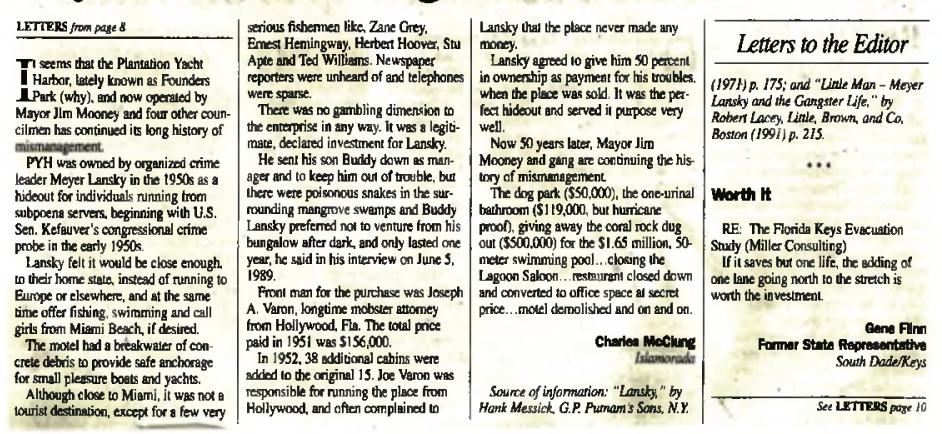




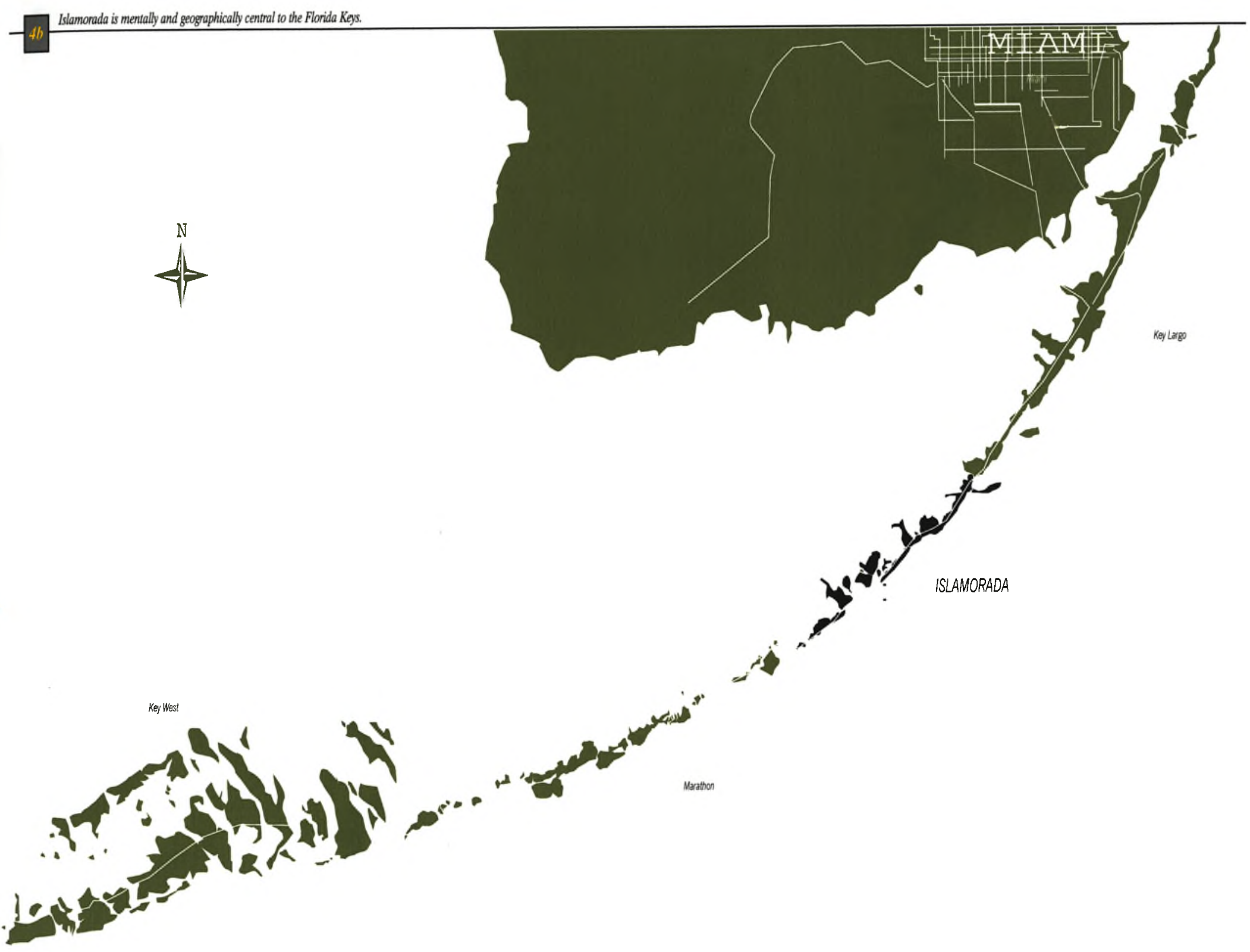




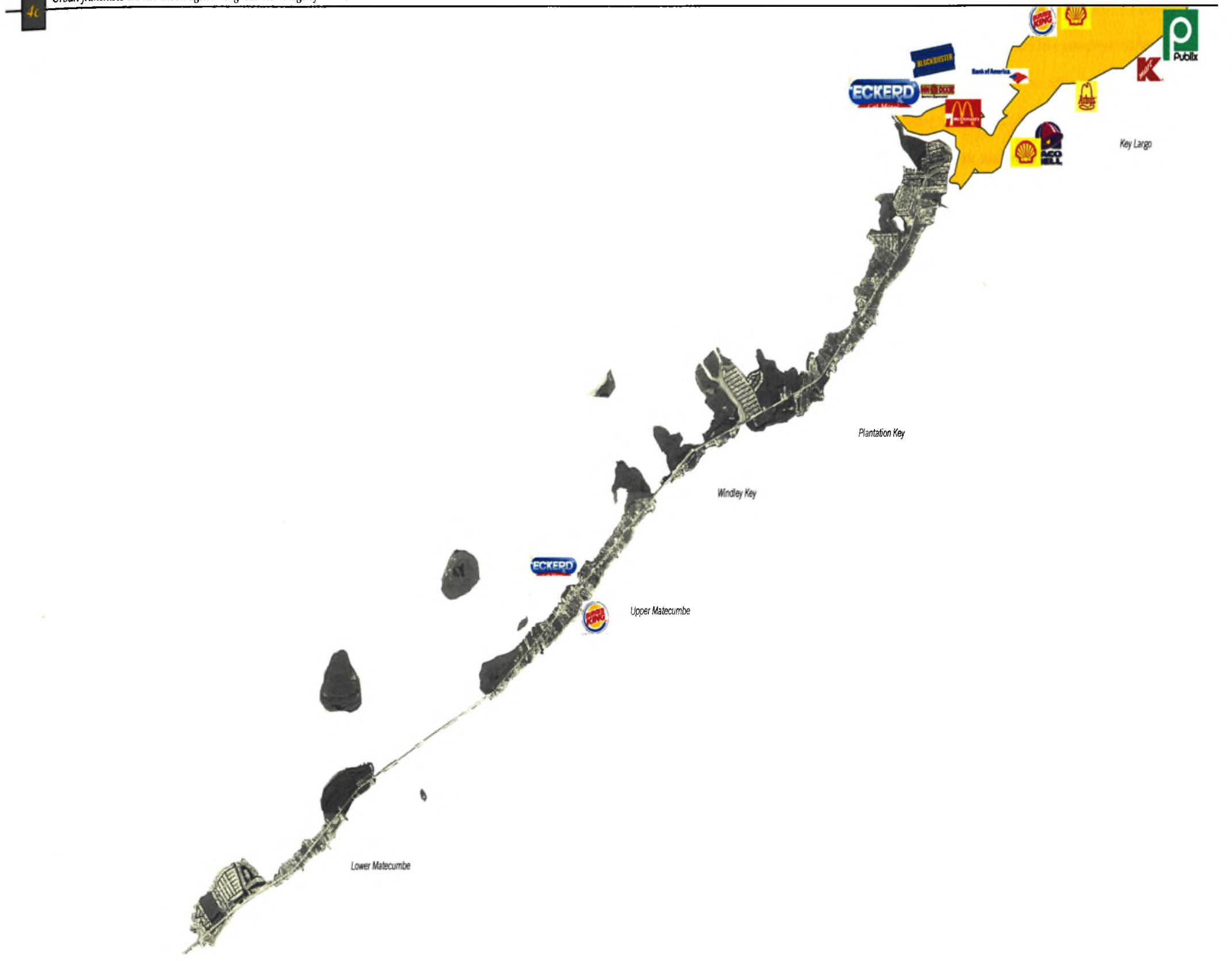




\subsection{Islamorada: Resources}

There is no cataloguing of information in the Keys. There are a handful of local newspapers, which are published weekly in Islamorada. To research a past article from such a newspaper is a unique experience. One must rummage through all the printed papers on site to be lucky enough to find what one's looking for. The staff member providing assistance might just be the author of the article. The image of The Reporter building demonstrates this unusual scale. (Figure $4 \mathrm{~d}$ )

The 'unplanned' nature of Islamorada and its villages demonstrates a unique island vernacular. Resources are randomly distributed along Route US1, the main corridor for automobile access in the Keys. (Figure 4e) Resources for Islamorada residents and others of the Keys extend beyond island boundaries. The Main Library is located in Lower Matecumbe Key. The Chamber of Commerce is also located here. On the otherhand, the Monroe County Police and Village Council Office are located disparately along Route 1 in Plantation Key. The Village hospital is located just north of Islamorada in Tavernier Key. There is no center to Islamorada, no city hall to obtain Village information.

\subsection{Routes}

Construction to string the Keys together began in January of $1928 .{ }^{4}$ Since then all vehicular travel has been dependent on the access of US1. Historically, before US1 and the connection of land had ever been envisioned, the water was the main resource for communications. (Figure 4f) The Florida Bay and the Atlantic ocean, which surround the Keys, were the significant routes for travel. Lighthouses guided the travelers through foreign waters. Indians, boaters, residents and tourists traditionally have always congregated by the waterline in the Keys. Islamorada, famous for its harbors, is also famous for being 'sports fishing capital of the world.'

\subsection{Founders Park}

Historically, marinas and harbors began to rise between the boundaries of islands in the Keys. Most of the harbors in Islamorada are economically set up for tourism with large hotels and tourist lounges. The Plantation Yacht Harbor, located in the middle of Plantation Key, was once also built for tourism. The Plantation Yacht Harbor, now called 'Founder's Park,' has recentiy been acquired by the new Vilage and declared primarily for the locals. The residents of Islamorada are free to enter while other visitors must pay a small fee for usage. (Figure $4 \mathrm{~g}$ )
Today, visiting boats, docks, picnic tables, a small beach, tennis courts, an Olympic size swimming pool and more makeup the variables of the Park. Large, green, unused lawn spaces with hammocks have been preserved free from struc tures. The VIllage Council recently adopted the old harbor restaurant building as their office space. This office is located by the harbor docks. (Figure $4 \mathrm{~h} \& 4 \mathrm{i}$ ) The dock office, changing rooms, and village meetings also reside in this space The beach is just a small 20 yard walk from the Offices. This immediate area, nearby the Village office is therefore considered the most activated area in the Park. It is a central location for many activities. The interaction between persons visiting the Village Council and persons visiting the beach and docks make for an interesting environment. Interestingly enough this business-combined-recreational setting represents the character and context of the Key's landscape; a richly mixed environment where businesses come for retreats and others come for recreation, relaxation and social interaction.

\subsection{Conclusions: the Solution is a Program}

The goal of this thesis is the development of a solution for Islamorada's misinformation problems. The information in this chapter recognizes a challenging proposition: to design a 21st century information system for a Village bathed in island tradition. Native 'conchs' as well as those wishing to escape the structure of the mainland are apt to be suspicious of modern intormation processing. The desire to be linked to the age of technology is often accompanied by a hands-on approach to problem solving. However, residents of the Village still desire to be connected and participate in the advancement of communications. A progres sive digital information system, which provides simple and non.intimidating access to information for the locals of Islamorada is the goal of this thesis. From the analysis presented in this chapter, a location for the proposed facility was chosen in the newly adopted Founder's Park. The Park's central location to Islamorada, the harbor, the Village Council and it's designation for locals affords a unique opportunity for an information facility.

The citizens who may access and use information within this proposed facility include youths, seniors, disabled, business community members, conservationists, sports-fishing enthusiasts and historic preservationists - all considered locals of Islamorada. The needs for an information access facility in Islamorada are similar to the programmatic needs of an advanced technical library. Most of the spaces for the Center were taken directly from the technology plan of the Nova Southeastern Technology Library, yet consolidated into the needs for a center within the context of islamorada. (Figure 4j) This proposed facility does not reimvent the library model, but rather repackages it in a progressive way, indigenous to the context of Islamorada. 

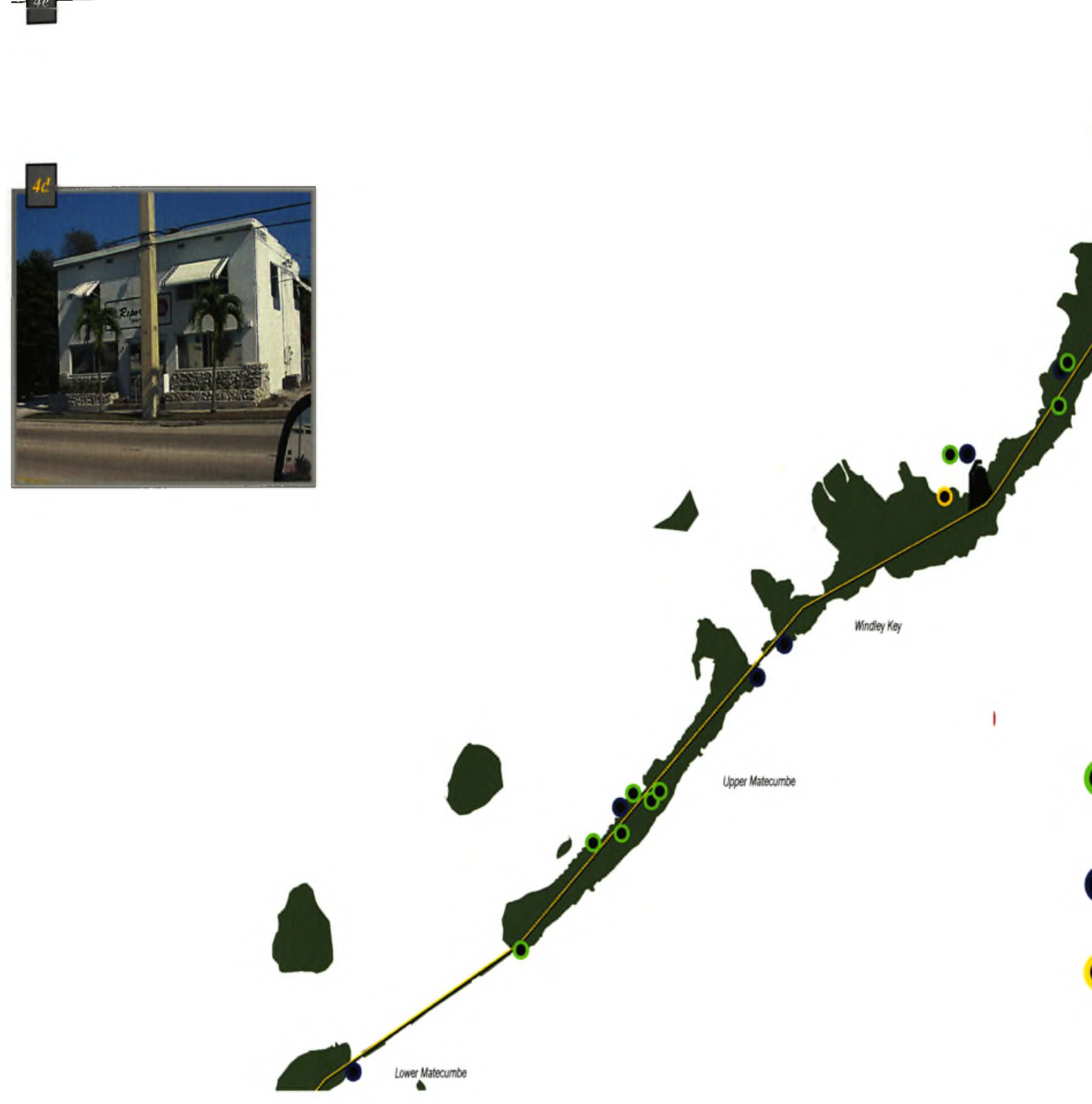

libraries, book stores

newspapers, schools, post offices

municipal offices

village services:

churches, hospitals, police,

marinas, parks

regional information access:

US1, antennas, satellites

radio stations 

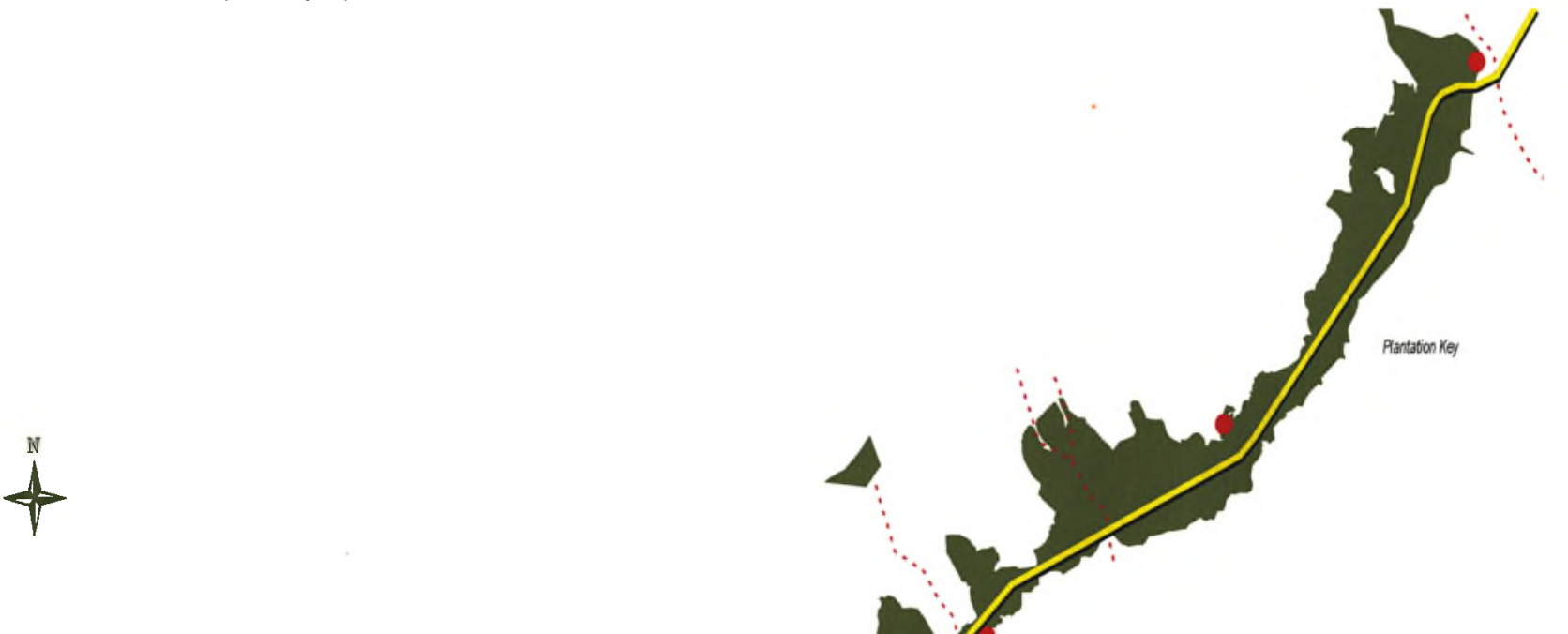


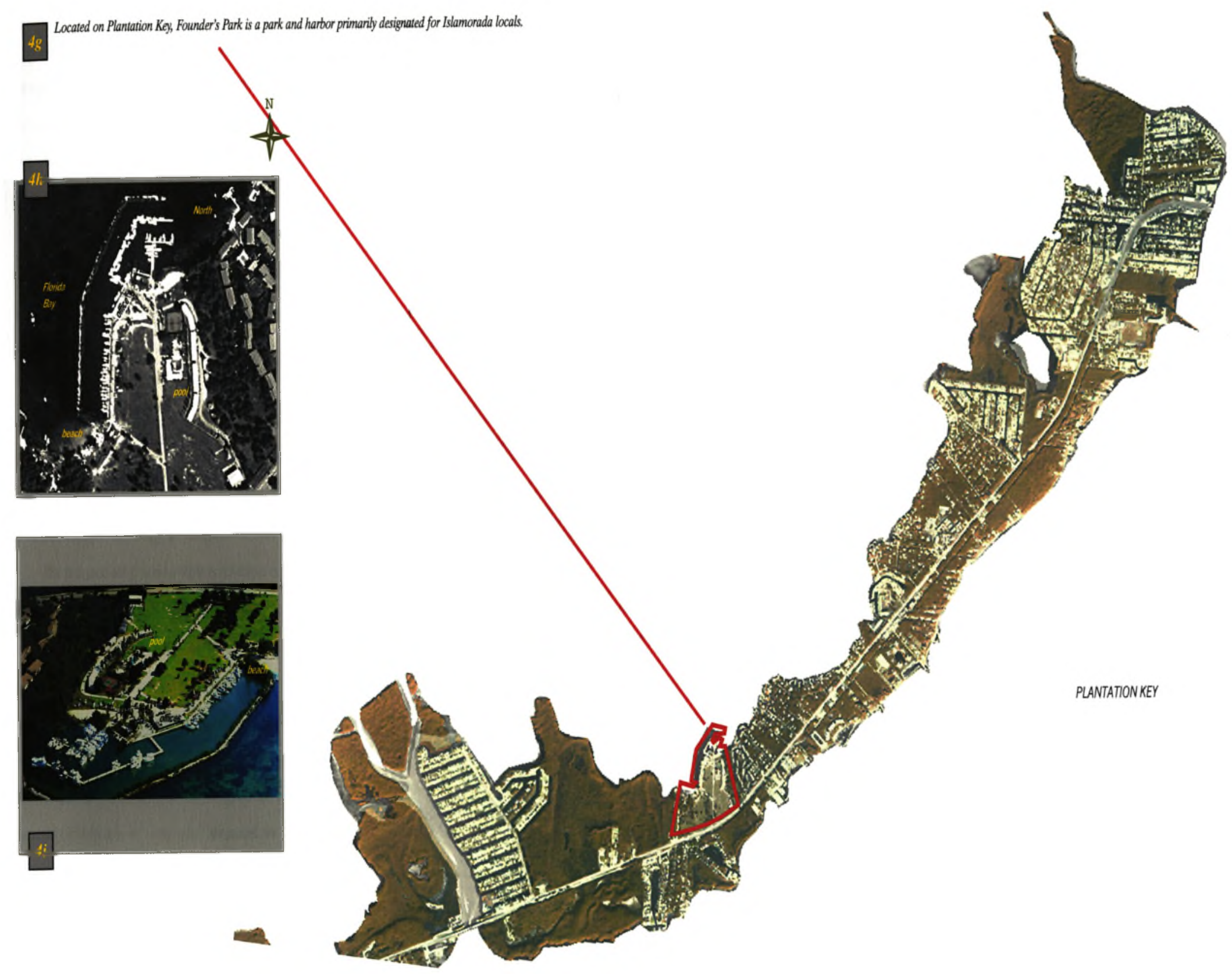


Essentially the objective of this facility would encourage open and responsive communication, which empowers the community to participate in fact finding, development of decision alternatives and education regarding potential impacts on the Village. For example, a group of Manatee Preservationists may use the Resource Center to retrieve and organize data into a presentation to obtain a research grant from the Village Council.

This service center will also provide local residents with virtual connections to the mainland of Miami and beyond. If a resident should need a book not available in the Keys, he/she may request the book electronically from this Digital facility. The book would then be sent to the Center for the resident to borrow. Locals could also use this facility to research the islands history and download local survey maps for redevelopment of their house or business. Boaters could download and print GPS maplike technology for navigation in their travels.

This proposal will provide a digitally advanced computer system for Islamorada locals, which can be accessed by a minimum of twelve individuals simultaneously. Conclusions gathered from the Cranbrook and MIT analysis show that information spaces of the future will be based on surfaces within environments. A series of information and meeting environments, with projection surfaces, are designed for different types of interactions. A large area designated for Village Council meetings links the Village Council office with this new information access center.

\section{Introduction}

Technology Planning Forms:

Classroom of the Future

Compact Shelving Area

Computer Server Roam

copying Center Exhibit Area Exhibit Area

Gift Processing Roo

Individual Síudy Carrels

Institute for Retired Professigna

Knowledge Navigation Cente

Loading Dock/Mal

Loulie Distribution Syśem

Media Distribution

Microloms Area

Mults-purpose Ayditorium

Multimadia Lab :

Punchdown/Com

Staff Lounge - NSIDE OLD

Table and Chair Seating

- University Archives

- Dentranceslexis

1 (10) Réntar
The Facility will also house a small office-like space for a librarian who will help with the mediation of information. Office space for a technician is also required. A small storage space will house Interlibrary Loan requests as well as space for the rental of media equipment. Most information will be transported digitally. Therefore, a small space for a Wide Area Access Network (WAN) is needed. This WAN system would be wired to Satellite dishes above or nearby the Resource Facility.

\section{TABLE OF CONTENTS}

Administrative Offices I MED/ATOR/ LBBRAR/AN

Cliculation and Reserves STAIRWAY DIELEVATOR

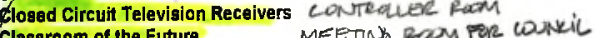
MEETIN ROOU POR WNKIL

AREa 1 TELH SPEZAACLST PART TIME

I serviar racam

Printikt ceortor

(ii) Current Journal Display

i printinh center

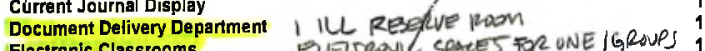

Eugrrani saAces FOR UNE jGRoves 19

Reference Desk,

Security - Surveillance System

24 Uplinking-Downinking Facility - SATEUTE AS BUILDINR

PARKING - ONSDE OLD REST

BDithraOMS - DNSIDE DLD REST

Notes

1. "slamorada, Village of Islands" was created in the "House Bill No. 1265 , The Laws of Florida [database on-line] (Tallahassee, Fl., Office Secretary of State, chapter 97.348, May 29, 1997, accessed on February 18, 2001); available from http://isiamorada.fl. us/village charter; Internet.

2. Dr. Patrice Gerard, interview by author, written recording Islamorada, Fl., February 18, 2001

3. "Goals, Objectives and Policies: Land use," Islamorada Comprehensive Plan Draft jdatabase on.line] (Islamorada, F., Village Council, chapter one, February 20, 2001, accessed on March 4, 2001); available from http://islamorada fl. us/comp plan; Internet.

4. John Viele, The Florida Keys: a History of the Pioneers (Sarasota, Fl. Pineapple Press, 1996), 131.

5. Ibid., 33-57.

6. Ibid., 99.100

7. More information about Wide Access Networks [WANS] and other information technology is found in the authors, "Data

Intormation technology is found in the of Gustav Peichl's ORF Studios" (Miami: Fiorida International University, research in Building Technologies, Fall 1999), 1.14. 


\section{CONCEPTS COMBINE}

\section{FOR THE FRAMEWORK OF AN ACCESSIBLE CENTER}

5.0 Ergonomics and Information Access

The previous chapter demonstrated why a digital Information facility for Islamorada is needed and what such a space should consist of. As previously mentioned, locals of the Keys are attracted to the secluded, peaceful atmosphere of the island environ. ment as opposed to the demands of a fast.paced city.life. Therefore, this facility should be non-intimidating, easily accessible and ergonomic to the residents of Islamorada.

What exactly is meant by the term 'ergonomic center?' The Cranbrook Industrial Design projects discussed in chapter II concluded that the current forms of modern information technology do not speak in a natural human language. The ubiquitous box designs of today's computers, monitors, televisions, stereos, etc... are mystery objects which have alienated users from the ease of understanding them. The students discussed, developed designs of systems which considered the most important element of the object to be the servicing it provided to the user. When the senvice of a product, rather than the beauty of the form, was designed, the fina object resulted in a more meaningful dialogue between itself and the user. The interaction with the information product was designed for a pleasant experience. These experiences, these ergonomic interac tions, are the uiltimate goal for the proposed Intormation Center:

While the Cranbrook experiments resulted in ergonomic forms, the MIT experiments in chapter III conclud.

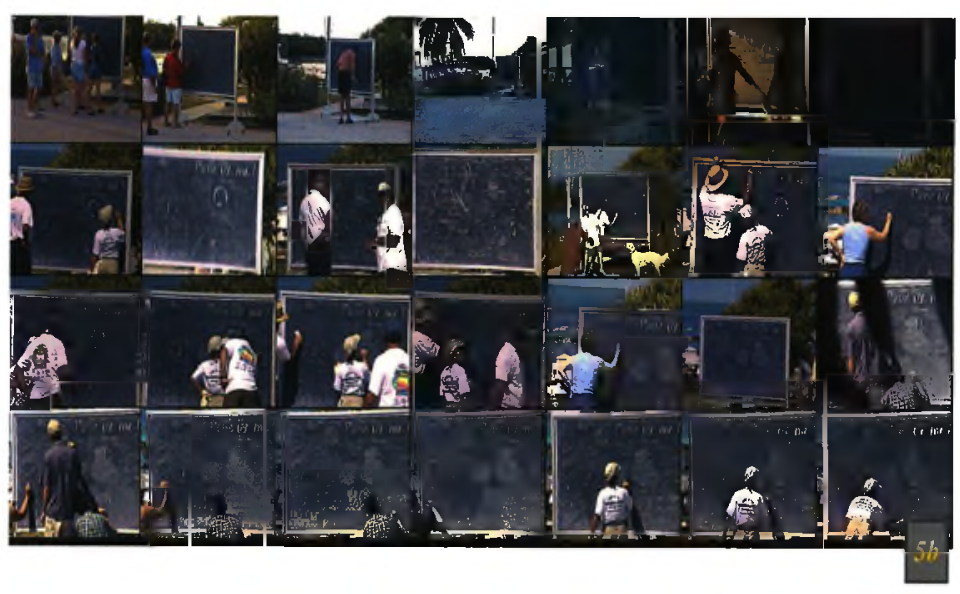

ed that future interaction with information systems will improve when the environmental context is considered in the design. Therefore, this chapter continues to investigate the immediate context of Islamorada, specifically of Founder's Park, in order to develop an information center that is accessible to the people of Islamorada.
To design an ergonomic center that is also technologically advanced, the 'servicing' of the facility needs to be considered.

This servicing is viewed to be how the center would provide information access to it's visitors and how ergonomic that experi.

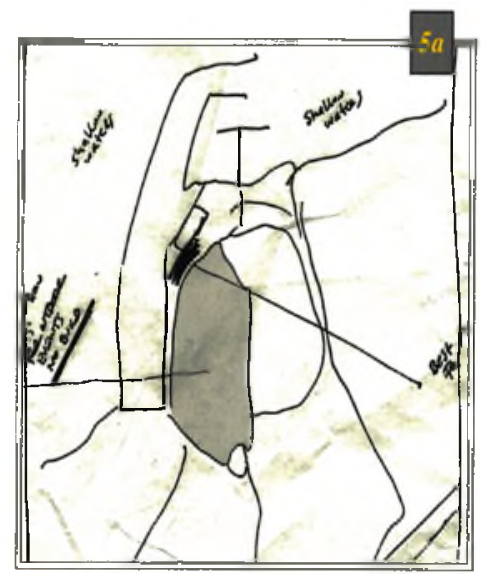

ence would be. This experience or 'interaction' is determined to be the dialogue between the people, the information and the environment. Locals within the intimate scale of the Keys frequently see their neighbors around town. Environments in Islamorada should be designed for such social interaction. Interaction with media for this island environment needs to be non.intimidating. Interaction with the environment considers the business and recreational society within Founder's Park. This inter. action was recorded in the following study.

The most activated area of Founder's Park was determined in the previous chapter. This site is where the business society and the recreational society intersect. This unique space is where the main road of the park passes by the Village Council office and the boats of the harbor. (Figure 5a) The people and environment were the two variables already existing to make this active space. A form of media was added to the site to record information interaction within the context of the Park. A 'chalkboard' was chosen to represent a non-intimidating, non-technical media device, a system which is familiar to the locals and therefore simple to use. It was assumed that observing the interaction around a chalkboard in this site would assist in the understanding of interaction within Islamorada and the Park itself. Atter two full days of recording human events around and on the chalkboard, a series of drawings, images and models developed in progression of the analysis. People seemed curious about the chalkboard's dislocation and were enthused to contribute information to it. (Figure $5 \mathrm{~b} \& 5 \mathrm{c}$ ) 
Initially, the event was deconstructed into the layers of information people left behind. Overlapping papers on a surface (Figure 5d) reflect different persons activities on the chalkboard over time. The result of the chalkboard displayed a surface, which showed traces of people's presences overlapping within a period of time. The information they left behind remained on the chalkboard until others, who arrived later would write over it or erase parts or all of it all together. Traces of people and their activities were left behind until no longer legible.

The markings on the chalkboard could be described as a graffiti of human personalities and interactions. Each mark represented a different individual's activity. The experience between the individual and their mark on the board was seen as their space of personal interaction. (Figure 5e) The model in Figure $5 f$ is a recording of the marks made on the board by the individuals. The marks, conceptualized as spaces of inter. action, were drawn into plaster molds. With these impressions, physical spaces became legible within the surface. These spaces, now recognizable to the eye, represented the intangible spaces of interaction, between people and the chalkboard. Just as the Magic Carpet project, from the MIT Media Lab, measures different body movements and amplitudes for sounds, this study came to measure similar human character. istics through chalk markings.

Figure $5 \mathrm{~g}$ represents the chalkboard in it's redefined state as a surface of measurement. A surface consisting of different spaces, becomes a wall for the recording of human traces. These traces represent varied interactions that occurred between the people within the context of Founders Park during those two days of analysis.
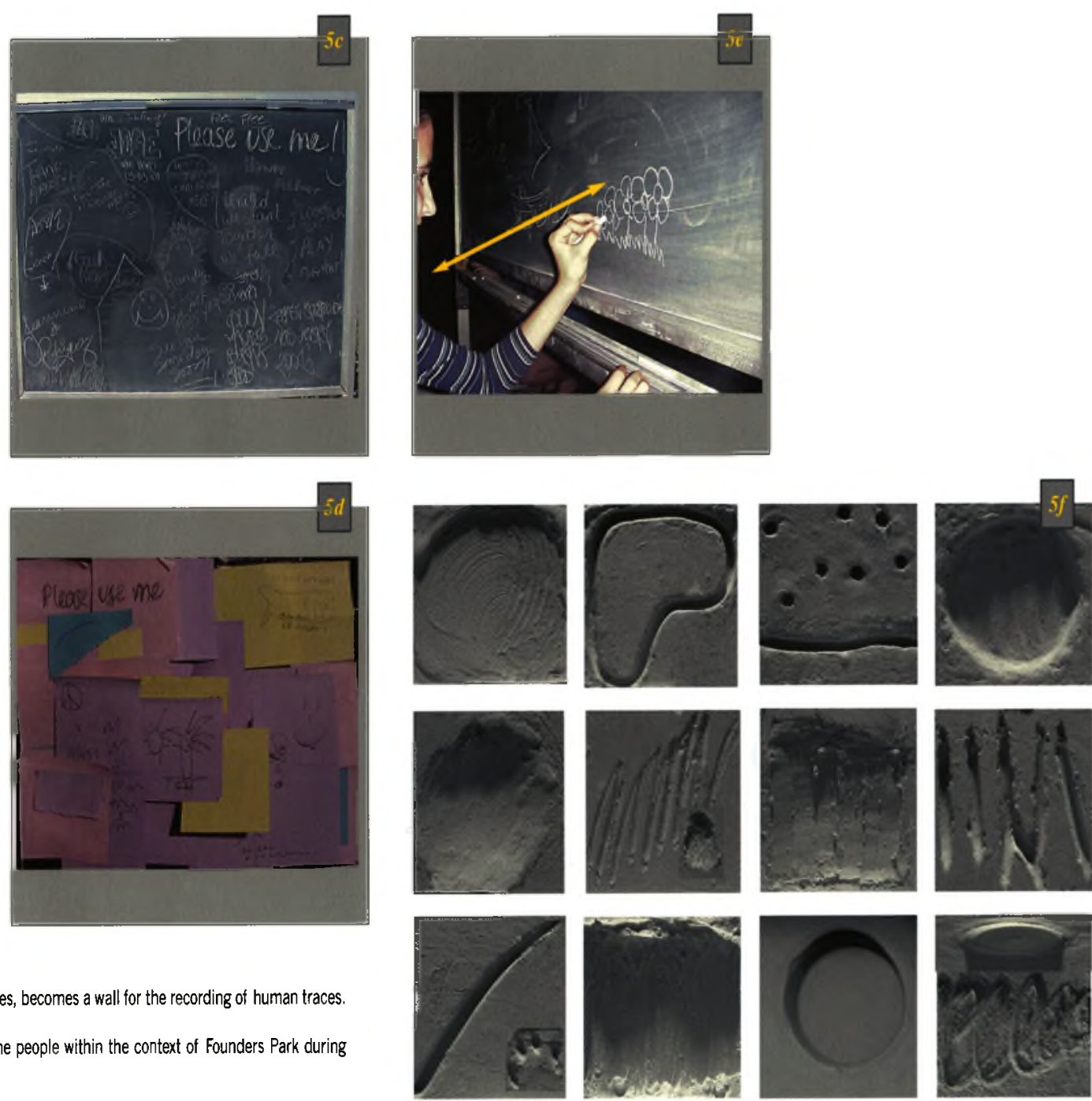


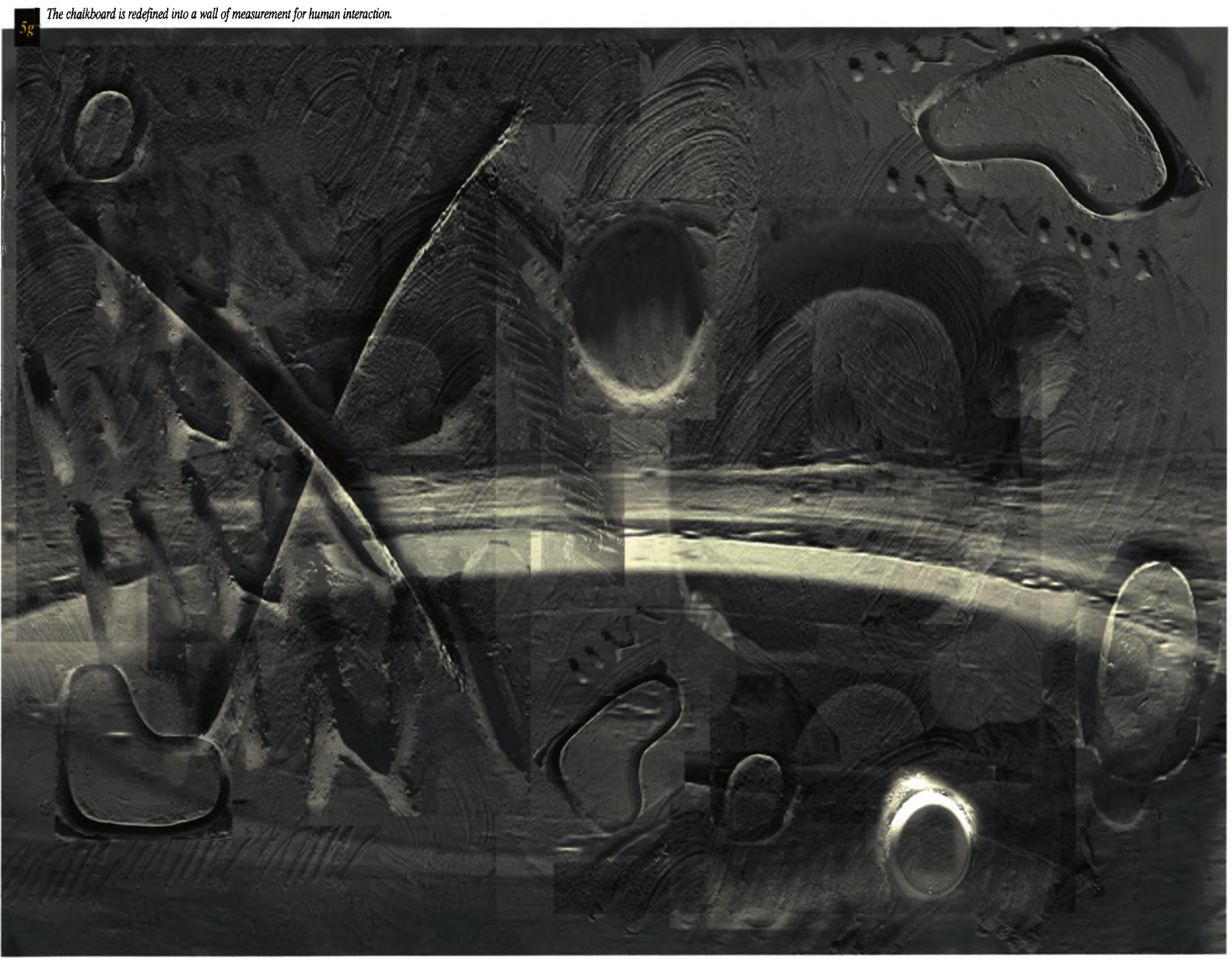


5.2 Surfaces and Wall Spaces

The chalkboard became a wall of symbolic spaces for individuals. People felt compelled to leave a trace of themselves on the surface of the chalkboard. The language of the chalkboard and it's surface was innate to the people and did not have to be learned. The investigation continued into the realm of how a surface and it's spaces could facilitate human interactions with information accessing. The model studies that followed began to explore how surtaces could be manipulated for different spatial configurations. (Figure 5 h) The desire to be able to touch a surface, customize it and to leave one's mark became a quest in the design for an ergonomic media center. Generic walls as surfaces and what is inside of them were referenced as structures which can be occupied. (Figure 5i) Models of different wall mechanisms were conceived in the design for human interaction with media surfaces. A concept of fixed walls emerged, with parts that could be moved and manipulated. Such a design is similar to the development of a computer's operating system, otherwise known as an interface. (Figure $5 j$ \& 5k)

As an operating system is a kind of language designed to facilitate the usage of a computer, the proposed Information Center needs to facilitate the accessing of information by it's users. Operating systems, such as Windows for the PC computer, are considered examples of interfaces. The concept of interface began to influence the design of the Center's walls.

Webster has defined interface as a "...surface that forms the common boundary of two bodies, spaces or phases," or "... a device that bridges different systems, people, ideas, technologies, etc." If the term intertace could be defined as much more than surface, could not the entire Information Access Center be designed as an interface? Surface structures such as walls began to influence the infrastructure and overall design of the Information Center. The facility was now declared an interlace for all interaction.
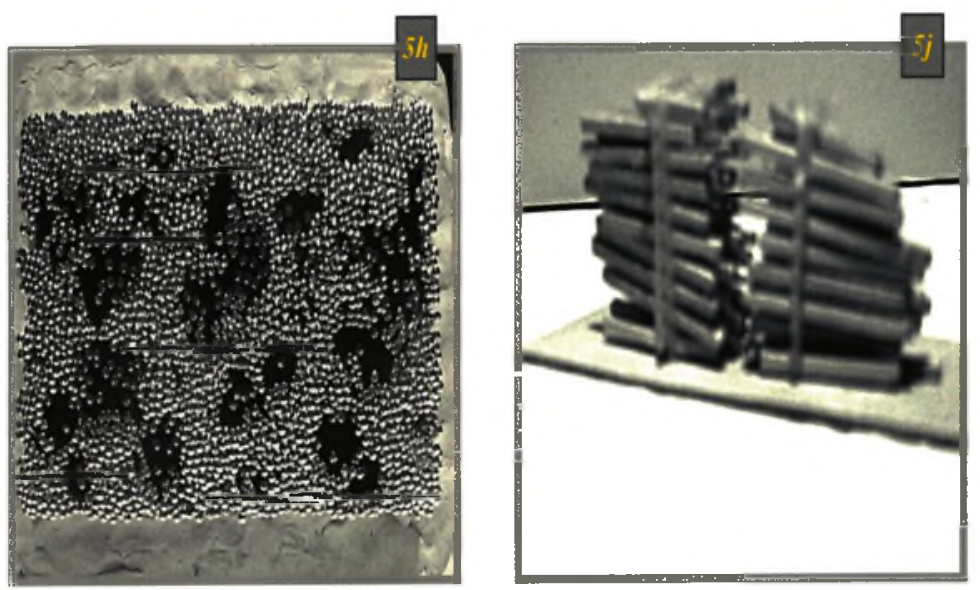

5.3 Vernacular: lighthouses, antennas and billboards The surfaces and their structures found in the Keys are unique. As the analysis continued, walls, surfaces and structures of the Keys were investigated. The history of media structures in the Florida Keys began with the lighthouse building. Historically, lighthouses were significant resources of information. The light at the top of the vertical structure navigated boaters through foreign waters. Caretakers, who resided within the structure, were responsible for recording water and weather conditions to inform those on land of possible disruptive weather conditions. (Figure 5L) The symbol of the lighthouse represents a sense of history and comfort to the Villager. The proposed information center is seen as a facility for one's navigation through the information world. Ideas pertaining to the height, size and surface of the Resource Center were therefore conceived from the poetic notion of the lighthouse artifact. Concepts for the image of the facility, to 'illuminate' one with information, also became framework for the proposed Information Access Facility. (Figure 5m)

Other media structures frequently located throughout the Keys off Route US 1 are those of radio towers. (Figure $5 n$ ) Not only do these towers have the similar vertical presence as lighthouses, but the structure is also a symbol of communication travel. Landscape in the Keys is fragile. To dig into the landscape for fiber optic infrastructure is ecologically 
dangerous to the waterline and native species. Most information travels through the air in radio waves. Structures that concern themselves with the access and use of information, such as antennas, physically address the sky for appropria. tion of air waves. Referencing the vernacular of these lighthouses and antennas, it became obvious that the Information Access facility should be a structure which engages the above. Figures 50 and $5 p$ are drawings which illustrate these ideas. Not only does the center physically communicate with the sky, but the interactive surface of the structure is also integrated into the conceptual framework for the facility.

Wall-like structures such as billboards, also provided insight into the design of the Information Center. As US1 is the primary route for locals and tourists, billboards for advertising located along it's edge, compete with the views of the Keys' natural environment. (Figure $5 q$ ) The conception of billboards provided an opportunity to design a facility that is media acces. sible not only to persons in the interior, but to persons in the exterior as well. Artist Peter Greenaway ${ }^{7}$ creates successful outdoor spaces based on this notion. (Figure $5 r$ ) The large lawns in Founder's Park were recognized as opportunities for human interaction with the exterior, green space. The location of the most accessible lawn in the park molded the general placement for the information Center. (Figure 5s) The Center would face the great lawn, presenting itself as a tall, digital billboard.
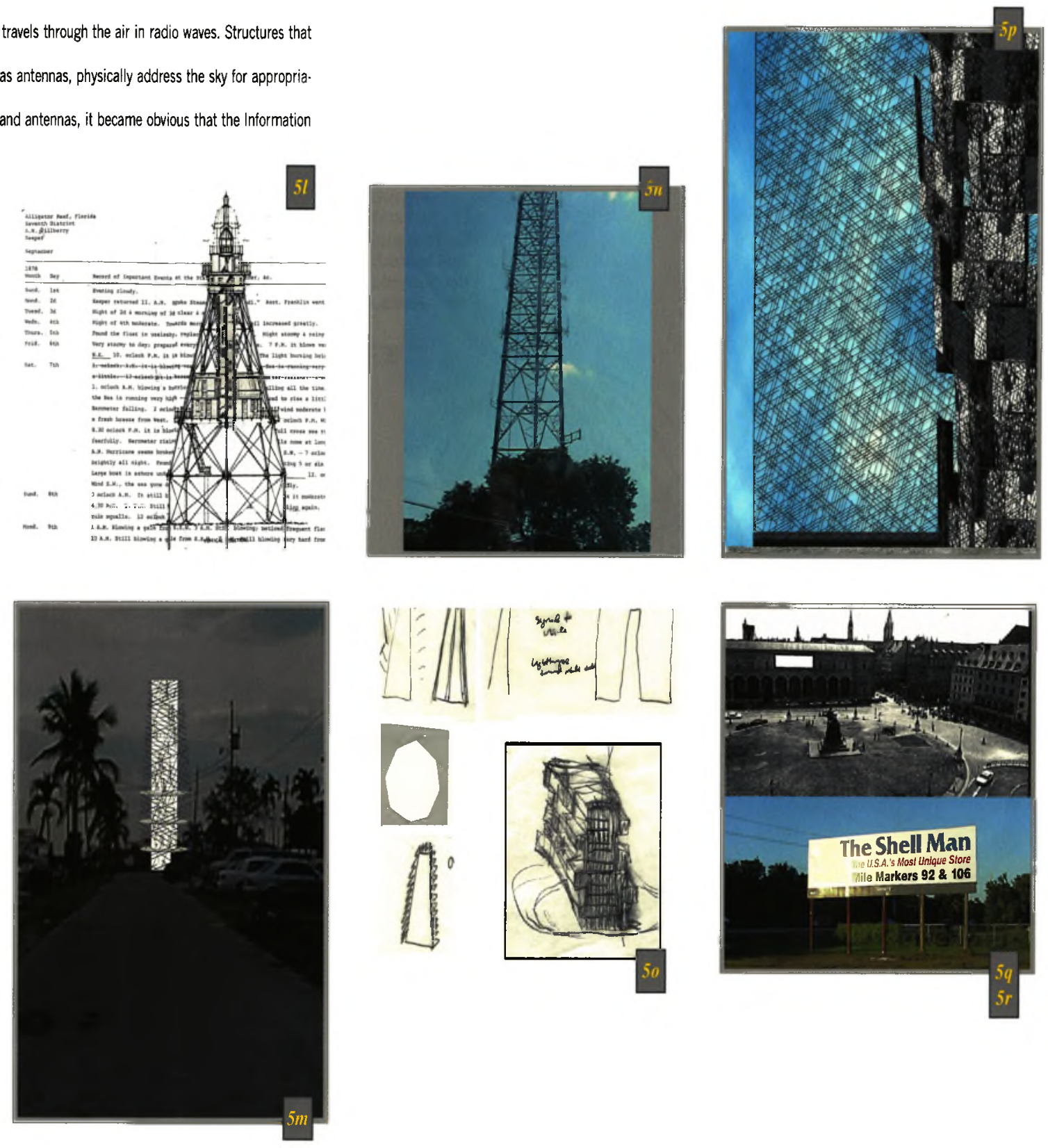
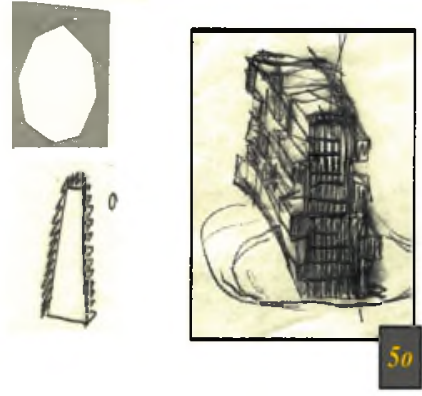

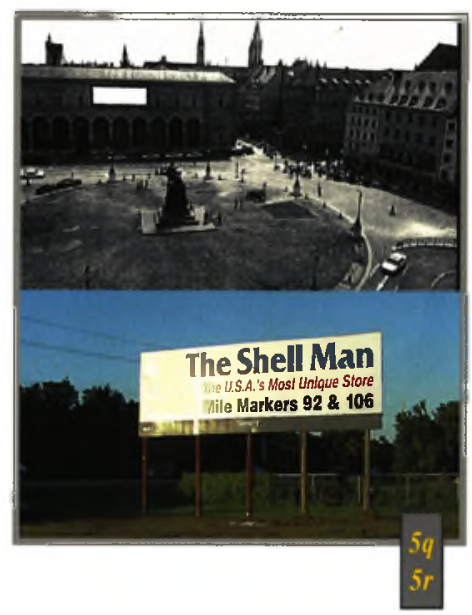


After the location of the Facility had been justified, specific site analysis of the primary area was conducted. The location of the great lawn, along with the effects of sun on the given area, determined the angle of the structure. Founder's Park is located at approximately 24.5 degrees south of the equator. Figure $5 t$ displays two stereographic sun diagrams, which represent the sun's location within Founders Park for the months of June and December. The sun is represented at noon time by the appearance of a small dot. The figure eight-like lines in the center of the diagrams, demonstrate the sun's path over all the months in a year, in proportion to the hour of the day. These images demonstrate that the most intense heat and sunlight is generated from the southeast during the summer days. Therefore, the frequently occupied spaces of the Center

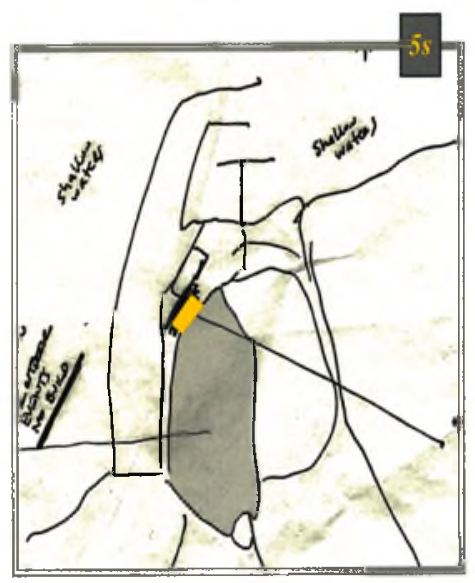
should be open to the northwest, for appropriate shading and cooler air. Figure $5 u$ displays the northwest shadows in reference to a tail, vertical structure within the designated location of Founder's Park, in the months of June and December. The sun's effect on the vertical structure of the Center would generate different articulations of program on both sides of the wall-like structure. Occupied spaces are to benefit from views of the northwest, where the Bay resides. The southeast skin of the structure, the side which faces the green lawn, would protect visitors inside from the heat and the incapacitating glare the sun would provide while accessing information.

\subsection{Scale in contert}

This chapter began with the measuring of human interaction for the quest of an ergonomic media center. The study of surfaces turned into a study for a soft interface between information and the human condition. When the term interface was analyzed, it became known that many variables can contribute to a successful interface. Opportunities for soft interfaces could take place at any scale. The way the building reacts with the Park can also be considered an interface. Site analysis once again continued. Interaction at all different scales within the Park needed to be addressed.

\section{Sun path \\ 5:00 PM \\ June and December \\ Founders Park \\ Longitude: -80 \\ Latitude: 24.5}

Tim

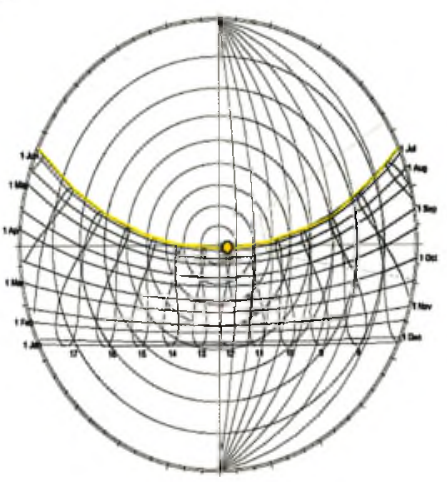

=xim

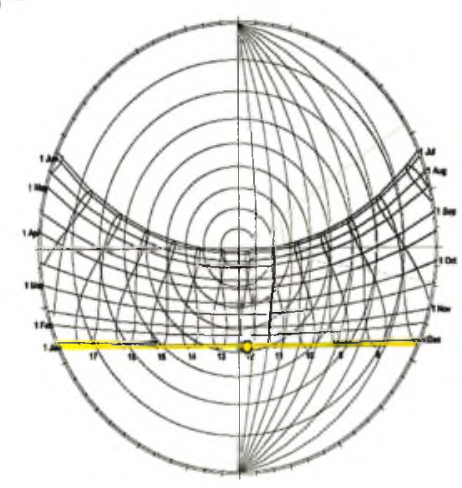

Sun angles

5:00 PM

June and December

Founders Park

Longitude: -80

Latitude: 24.5

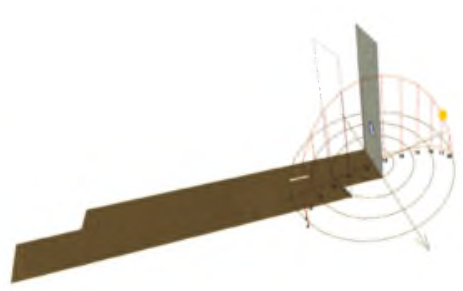

F

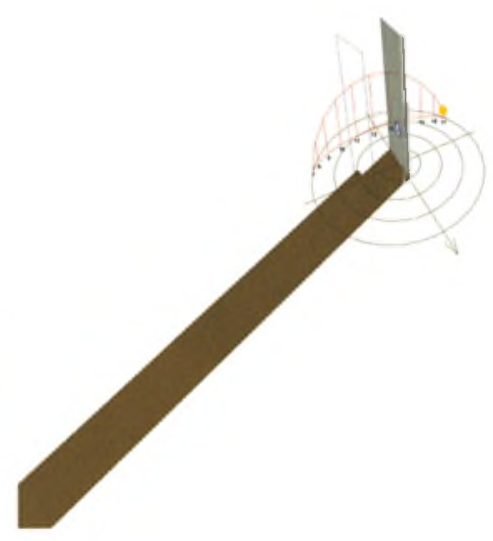


Investigations concerning the location and perception of the human in this space became significant to the organization of the Center. Three-dimensional diagrams, documenting important variables of interaction experienced at each level of the building, were generated.

The first scale diagrammed the interaction of the human body in relation to the immediate environment around the proposed Center's location. (Figure 5v.1) The black void represents the interior space of the existing Village Council office. The ribbed textures represent the variables of travel within the immediate vicinity; the road, the water, the docks and the grounds of moving activity. The flat texture signifies the unused land, such as the open green lawns, which consume most of the Park space. Silver pin-heads represent people activity within the area. Figure $5 v .2$ demonstrates the variables documented at this scale. They were generalized into three main components: the interior Village Council office space, the green dock space and the vehicular road that connects the two. Most activity was recognized within the offices, nearby their entrances, and alongside the harbor docks.

The next scale one would experience in the vertical infor. mation center would be one story up above the previous diagramming. At this level, the visitor would have views of the Park as a whole. (Figure 5w.1) Figure 5 w.2 illustrates the
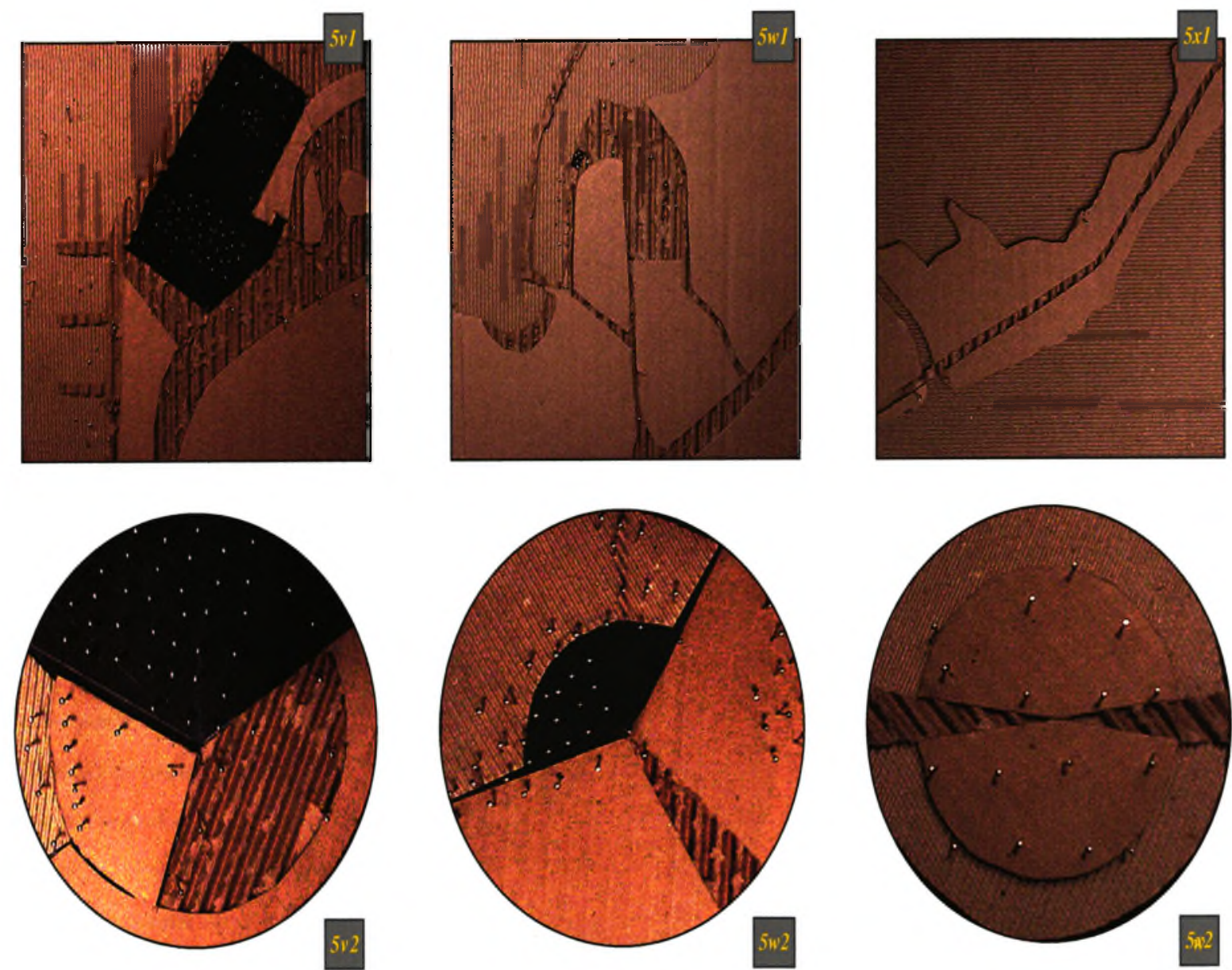
experiential interaction between the visitor and the park environment. Views originating from the site of Village office, are the green lawn space, the main entrance road to the Park and the western waters of the Bay. Most activity, at this level, is concluded to be near the Village Office, the docks and the Park's beach. 
The third scale a visitor would experience, would be as if one was floating above the Village. (Figure 5x.1) At this level, visitors are farther from their immediate location and have views pertaining to the community. Figure $5 x, 2$ illustrates the land cut in half by the existence of Route US1. The variables to experience would be the land, the water and the direct rip of US1. Interaction at this scale occurs on both sides of US1.

The surrounding variables become more abstract when one arrives at the fourth level of the proposed vertical structure. No longer are the immediate surroundings clearly articulated. The sky is what one sees. The feeting of interaction with the sky and accessing information from other lands abroad is the focus at this scale. Variables here consist of the bodies of water and islands of land located within. Activity generates on the land below, which one feels more removed from. A private connection with the world is felt at this level.

The final experience within the structure is what one would experience on the last level within a vertical building in the designated site. The top level of the building faces the sky and the intangible above. This scale is experienced through the knowledge of how information and light travels. The variables at this level are intangible and possibly more spiritual. The experience here is less about the human body and more about the buildings connection with the universe.

\subsection{Interface is redefined}

Interfaces have been described as surfaces, devices, etc., that bridge different entities together. However, the analysis from this chapter concludes that such connections take place at an infinite amount of scales, beginning with the body, mind, and concluding with the universe. "We naturally visualize an interface as the place where contact between two entities occurs. The less alike those entities are, the more obvious the need for a well-designed interface becomes..." Many different environmental variables have been considered in the conceptual framework for this information facility. When these variables are considered from a design perspective, then ultimately, this Center becomes one large interface in itself. The proposed center is described as an entity which negotiates between users bodies, user's minds, surfaces, information, the environment, the Village, and ultimately the universe. The final chapter mediates the current problem of misinformation in Islamorada through the design of a considerate interface.
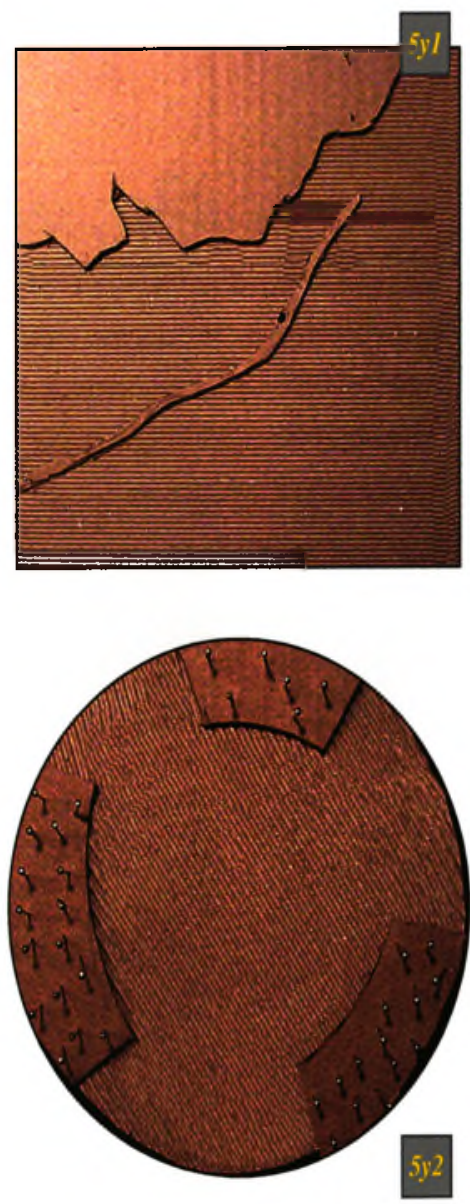

1. For a detailed discussion of this matter see the chapter on Cranbrook pp. 1.6.

2. Two full days of recording human interaction around the interface of a chalkboard were conducted. Author, Measuring Human interaction (|slamorada, Fl., Founders Park, February 28.29, 2001), video record

3. For a detailed discussion of this matter see the chapter on MIT

4. New Websters Dictionary and Thesaurus (Danbury, Ct: Lexicon Publications, Inc 1993), 504.

5. For a detailed history see Dean Love, Lighthouses of the Fiorida Keys (Sarasota, Fl.: Pineapple Press, 1998).

6. For information on the fragile Keys' ecology see Jeanette Gato, ed. The Monioe County Environmental Story (Big Pine Key, Fl.: The Monro County Environmental Education Task Force, 1991) 202, 230.232. For information on ecology laws see "Goals, Objectives and Policies: Land use," Islamorada Comprehensive Plan Dratt [database on-line]

(Islamorada, Fl.Village Council, chapter one, February 20, 2001

accessed on March 4, 2001); available from

7. Peter Greenaway, The Stairs: Munich projection (London: $M$. Holberton, 1995), 92

8. Information concerning the sun's location and shading properties is obtained from SQUARE ONE research PTY LTD, Ecotect software [database online] (Nedlands, Australia: The School of Architecture and Fine Arts, The University of Western Australia, Nedlands, Australia, 2001, accessed in January, 2001); available from hltp://www.squl.com; internet.

9. This part of the design process derived from understanding the philosophy of Phenomenology. The awareness of one's location in space is also considered in Rabinovitz's thesis. See chapter $\|$ on Cranbrook, p. 5.

10. "A surface that forms the common boundary of two bodies, spaces or phases," or "a device that bridges different systems, peo ple, ideas, technologies, etc." Websters Dictionary, 504.

11. Brenda Laurel, ed, The Art of Human Comouter Interface Design (Reading, Ma: Addison-Wesiey Publishing Company, 1990), xii. 
CONCLUSION

ARCHITECTURE IS DESIGNED AS INTERFACE
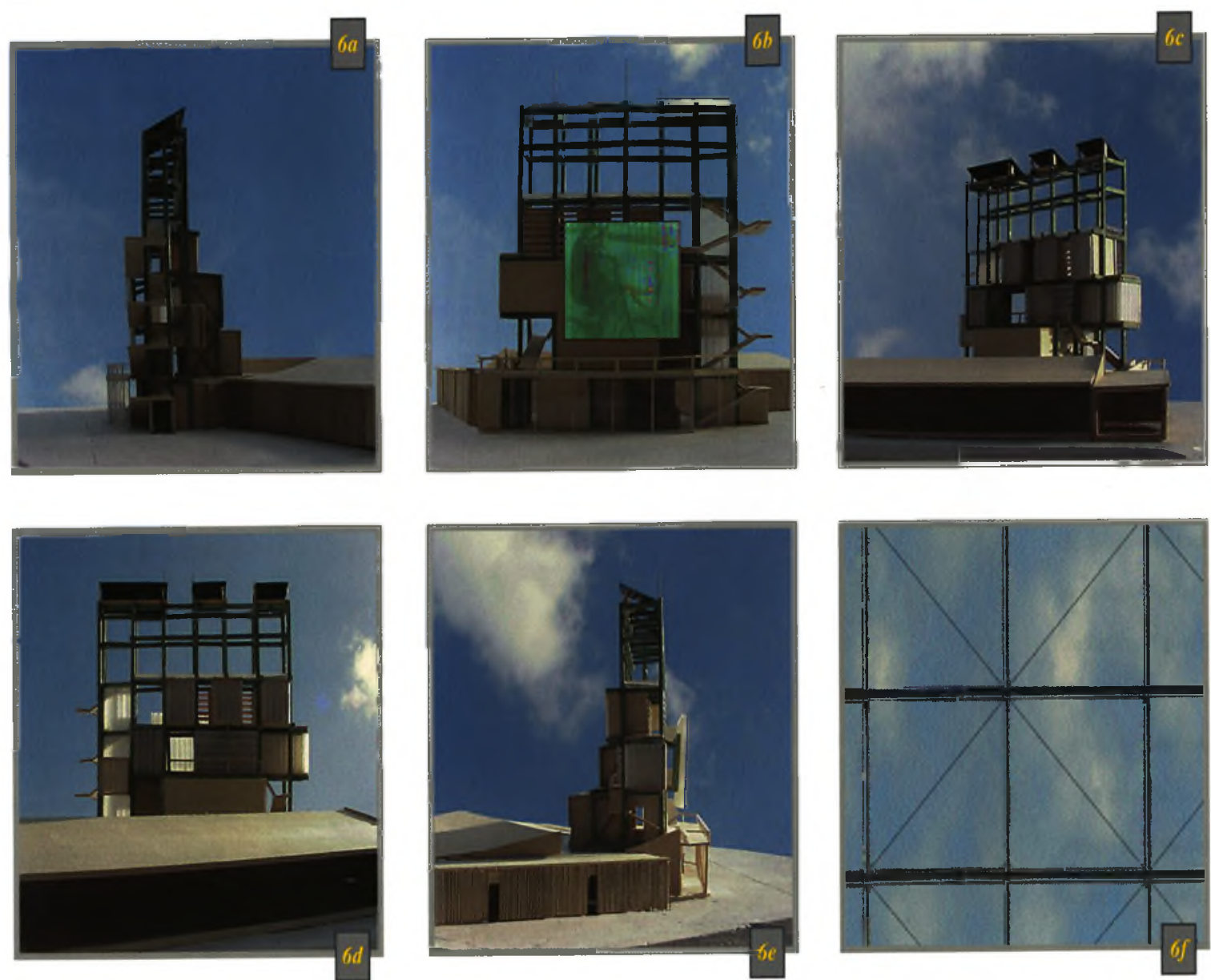
VI

ARCHITECTURE IS DESIGNED AS INTERFACE

6.0 A Digital Information Facility for Islamorada This thesis concludes with the design of a friendly digital infor. mation facility for the Village of Islamorada. This chapter combines the variables discussed in previous chapters into the design of an ergonomic interface - where one can access information in a simple and non.intimi. dating manner. The building is described in terms of interfaces between many different scales involved in the architecture, from the individual scale to the global. The structure and organization of the Facility is initially discussed as an interface for the vernacular character of Islamorada. The Facility is then discussed in terms of an interface for the community throught the design of it's ervelope and position within Founders Park. The interior spaces are explained as interlaces for interaction between the accessing of media and the visitors. Finally, the Center is described through the design of the architecture, as one consecutive interlace between Islamorada, it's residents and the information world.

6.1 Interface for the Vernacular: structure \& organization In order for the Facility to interface within it's environmental setting comfortably, it is designed to complement the surrounding vernacular. The Center, where many from the community meet, is placed in the area of the park where the most social interaction was determined.' (Figure $6 \mathrm{~g} \& 6 \mathrm{~g} 1$ )

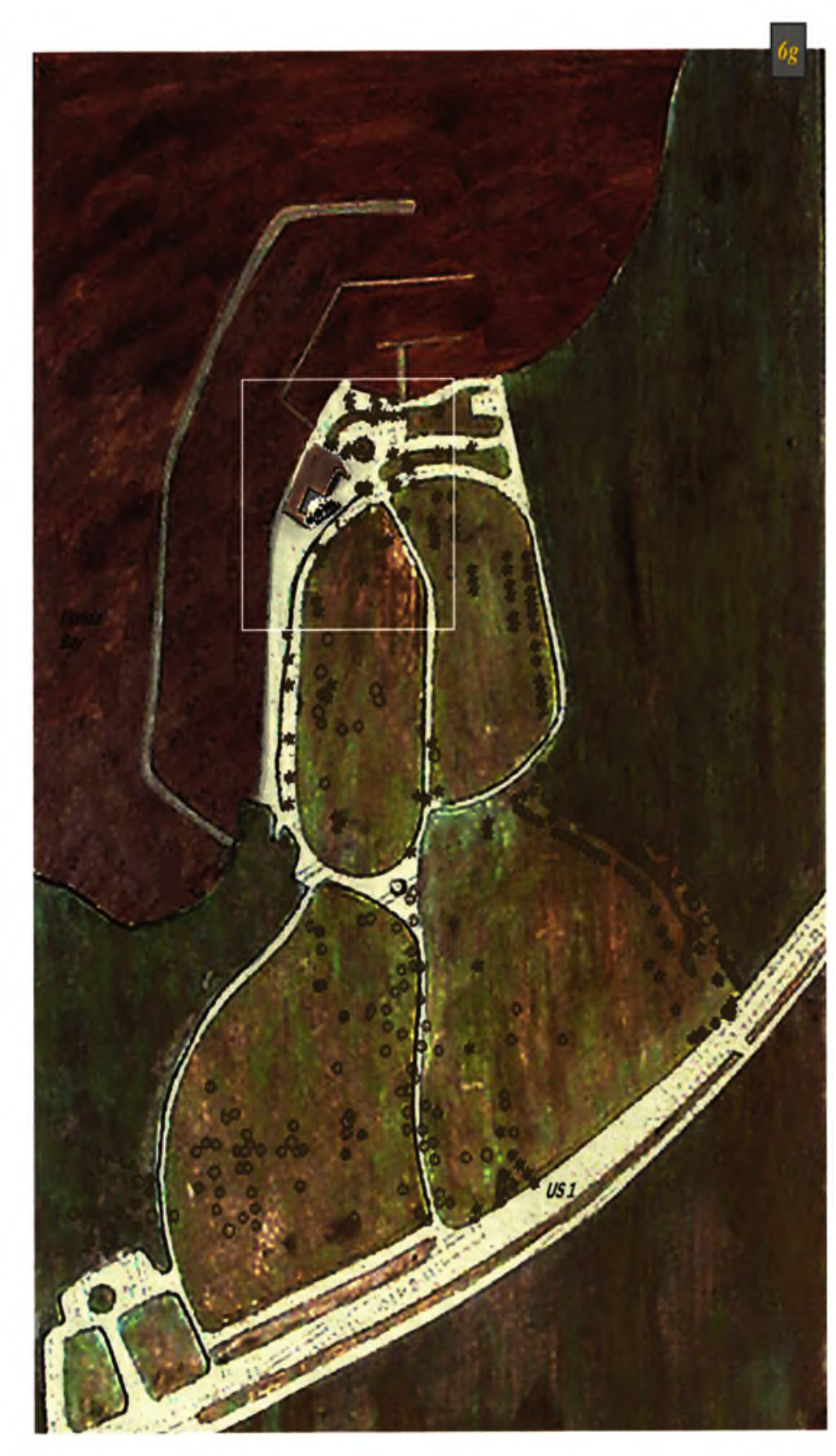

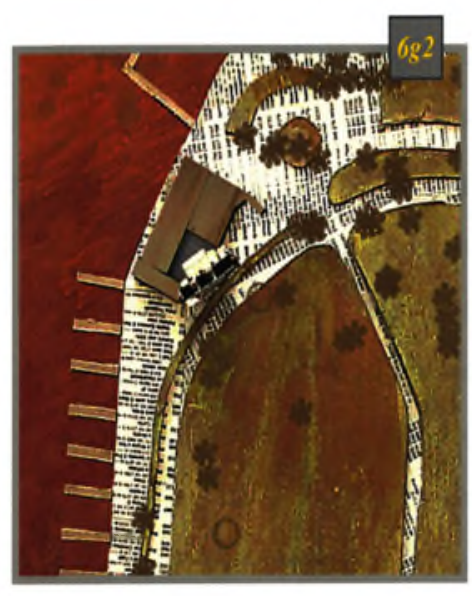

The structure of the Center also complements the other existing structures within the Key's vernacular. The illuminating and vertical presence of the Facility was influ. enced by the lighthouse discussion in chapter IV. The infrastructure of the Center derived from the reference of radio towers, which is also explained in chapter $N{ }^{3}$ Similar to the structures of these radio towers seen all along Route 1, steel I.beams, trusses and pilings support the Facility. (Figure 6f) This open-trussed structure allows for a variety of interior and exterior space configurations commonly seen in Keys' buildings. These kind of spaces, which blur the line between interior and exterior, were influenced by the climate, flat geography and natural views inherent in the Keys. Such spaces also encourage environ. ments of social interaction, which are demonstrated in the latter part of this chapter. 
The organization of the Center, otherwise known in architectural terms as the parti, was also partially influenced by the Islamorada vernacular. US1 is the only direct route that provides transportation through Islamorada and the remainder of the Keys. Circulation throughout the Center mirrors this notion. Information travels vertically through the a central 'server corridor.' (Figure 6h) In the plan view, people circulate through the Center's $60^{\prime}$ linear corridor. (Figure 6i) This central circulation artery is repeated on every floor. Entrances and exits, along with the other active spaces, are situated along these corridors, (Figure 6i) as all the activities in Islamorada are located along Route US1. (see Figure 4f) The Facility is harmonious with it's surrounding landscape.

6.2 Interface for Natural Resources: position \& skin The position of the Facility derived from site analysis investigations discussed in the previous chapter. To refrain from disrupting the Keys' fragile lands and natural ecology, the Information Facility re-uses previously established spaces. The Facility is designated as an annex to the existing Village Council office. The old building links to the new by the connection of the Community Meeting Room. (Figure $6 \mathrm{~m}$ )

The position and facade of the structure within the site, are based on two ecological variables: the sun's exposure and utilization of the great lawn space. The people, spaces and technologies within the Facility are
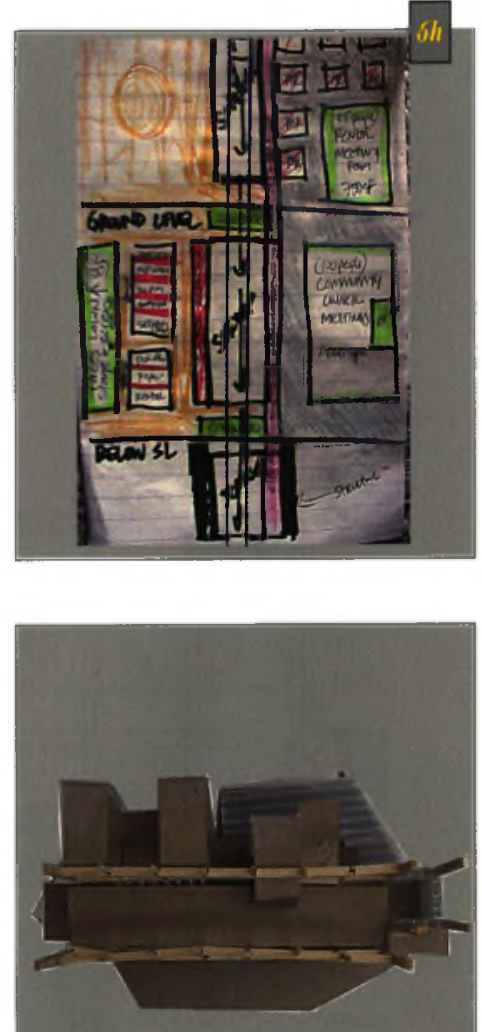

protected by the skin of the southeast facade, which does not allow incapacitating light and heat to enter. This facade also engages the unused green spaces of the Park with an all.encompassing 'digital billboard.' The impenetrable quality of this media surface not only allows for heat and sun protection for the Facility's interior spaces, but also provides movie entertainment and up-to-date bulletin information for the community at.large. (Figure $6 \mathrm{~L}$ ) The northwest skin of the building is more permeable due to the benefits of cooler air and less sun exposure." Most of the interior spaces are situated along this shaded side of the building, which also provides scenic views of the Florida Bay.

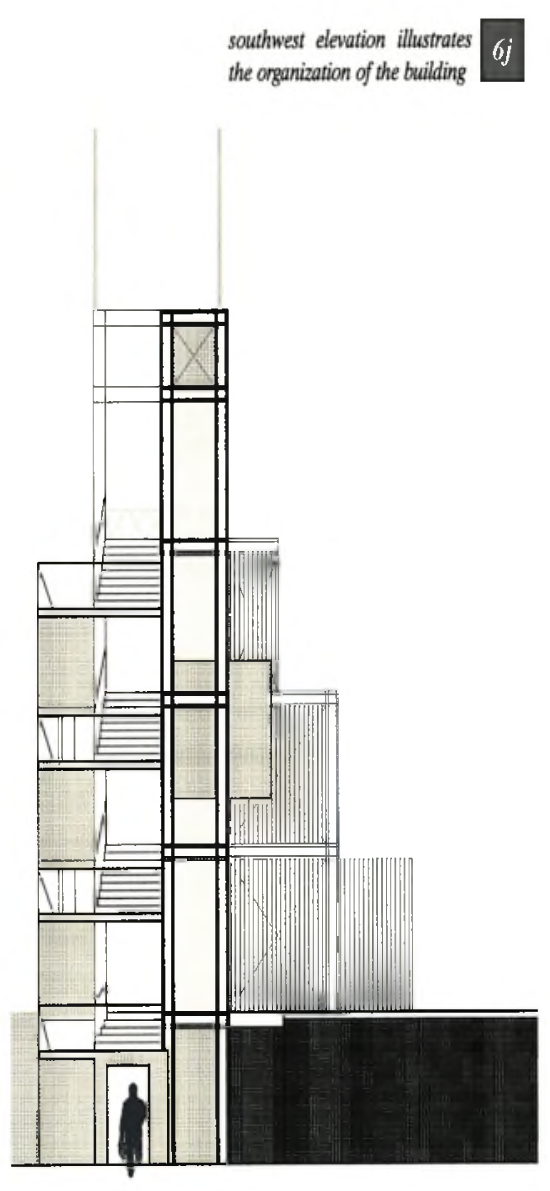
(Figure 6k) Both sides of the building are articulated differently. The image of the Center appears like a towering wall with layered facades. One side of the wall is solid and impermeable, while the other appears to be a frame for interchangeable parts. (figure $6 \mathrm{~L} \& 6 \mathrm{~m}$ ) Both sides of the wall are considered entities that bridge the gap between technology and the natural environment.

6.3 Interface for Mind and Body: media walls From it's beginning stages, this thesis has been committed to the individual's relationship with communication technologies. The Cranbrook projects in Chapter II suggested that consideration should be given to the 'servicing' of information as well as to the form of it's ervelope. The MIT Media Lab experiments discussed in Chapter III, noted how the environment plays a significant role in improving interactions between users and the accessing of information. The chalkboard observations in Chapter $V$, joined these concepts in the search for ergonomic interactions within an environmental setting. (Figure 5i) As a result of these explorations, the interior environments of the Center are designed primarily for media interac. tion. Similar to the MIT projects, Laser Wall and Magic Carpet(Figure 3e), information access is no longer limited to the computer box, but now encompasses any surface within an interior setting. 

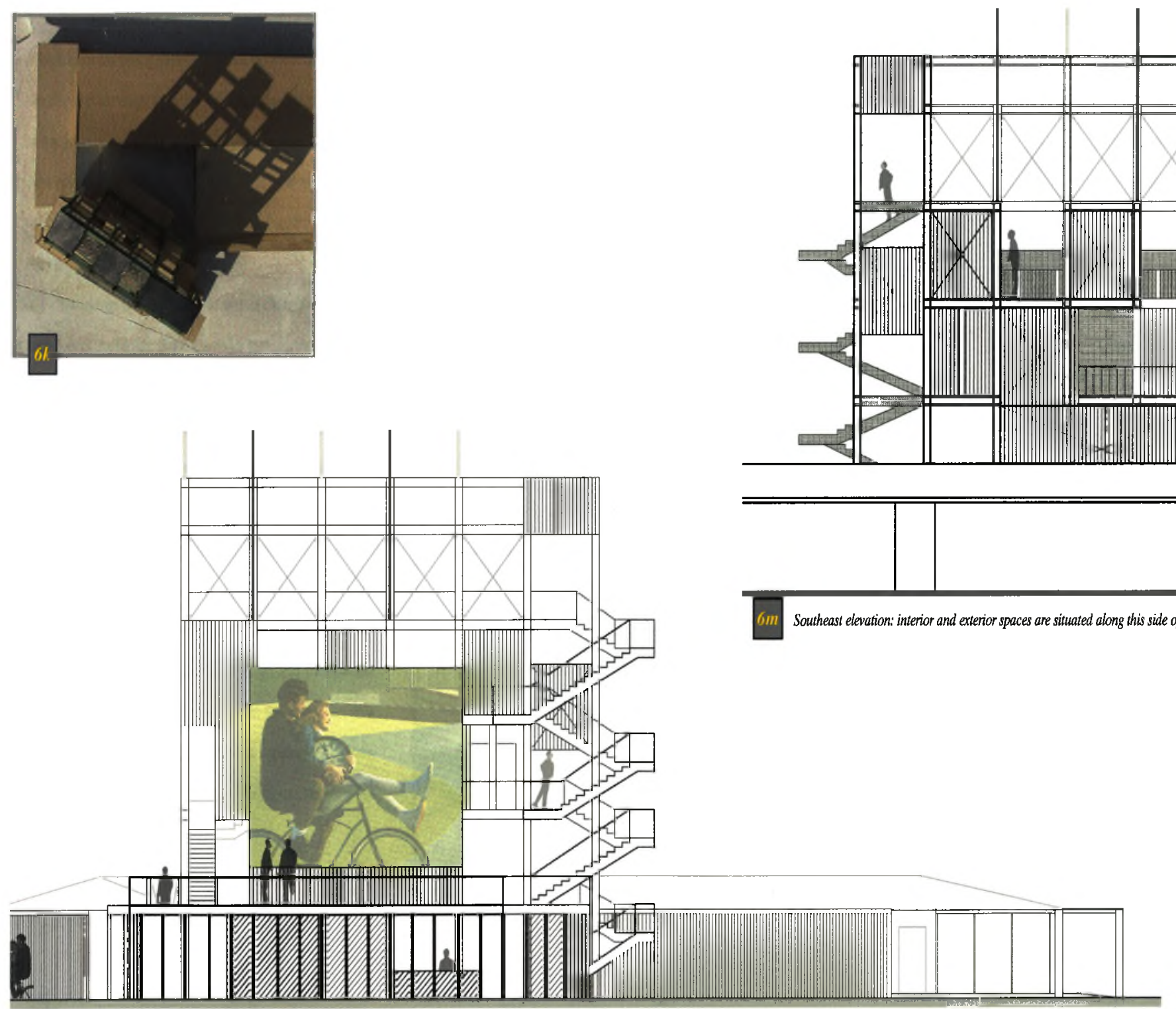

Nonhwest elevation: a large digital billboard is the protective skin for the Facility.

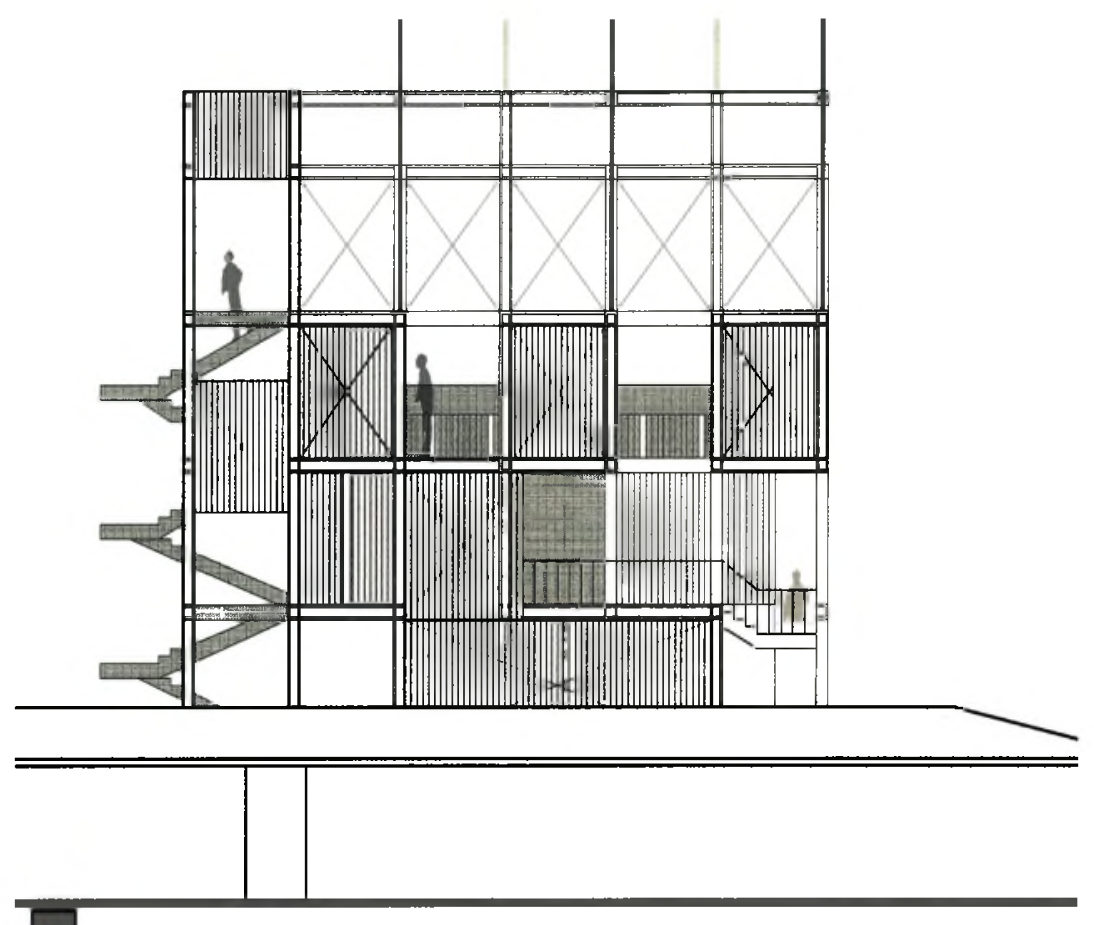

Southeast elevation: interior and exterior spaces are situated along this side of the 'wall' and engage natural views of the Bay. 
The media walls of the Facility are entirely made up of Liquid Crystal Display $(L C D)$ screens. Cameras and projectors imbedded in the ceiling above, recognize the movements of visitors below and project requested information onto the desig. nated area of the electronic walls. The height and width of each wall and each screen, in the Center's media rooms, are designed to the scale of the average visitor. (Figure $6 n$ ) The screen sizes were determined by the average size of one's hand and individual maximum peripheral vision. $L C D$ screens $\left(22^{\prime \prime} \times 22^{\prime \prime}\right)$ are used to tap into the today's information world.

The design of these walls located in designated areas on each floor of the Facility, allows the visitor to customize their inter. actions with information. Each screen can be pulled out from the wall, like sliding a drawer out from an armoire. These moving squares create privacy barriers from other visitors accessing information nearby. (Figure 6q) For individuals who require more space to access and organize information (for example, for the preparation of a presentation), parts of the wall or the entire wall can be used. (Figure 60) This allows users the opportunity to retrieve data among themselves or within groups. These media walls are designed so each user can define their own interactive space of comfort. The walls thus become ergonomic interfaces that bridge the interaction between individuals and the access of information. (Figure 6p)

6.4 Interfaces and the Development of a Plan

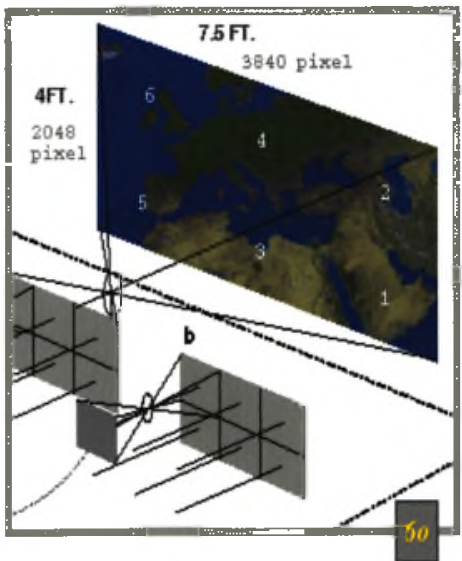

The organization of the activities within the Facility is based upon the environmental variables explored in the previous chapter. Each plan is described according to the phenomenon of how each level would be perceived by the visitor. The ground Hloor plan is designed as a system of connections between the visitor's initial approach to the Facility and the immediate variables within the site. (Figure $6 r$ ) Two main entrances, connected by the $60^{\prime}$ corridor, join visitors from different areas of the Park. One entrance is located parallel to the entrance of the Village Council office. A second entrance is located on the other side of the Facility, nearby the harbor. People arriving by the water, those coming from the offices and individ.

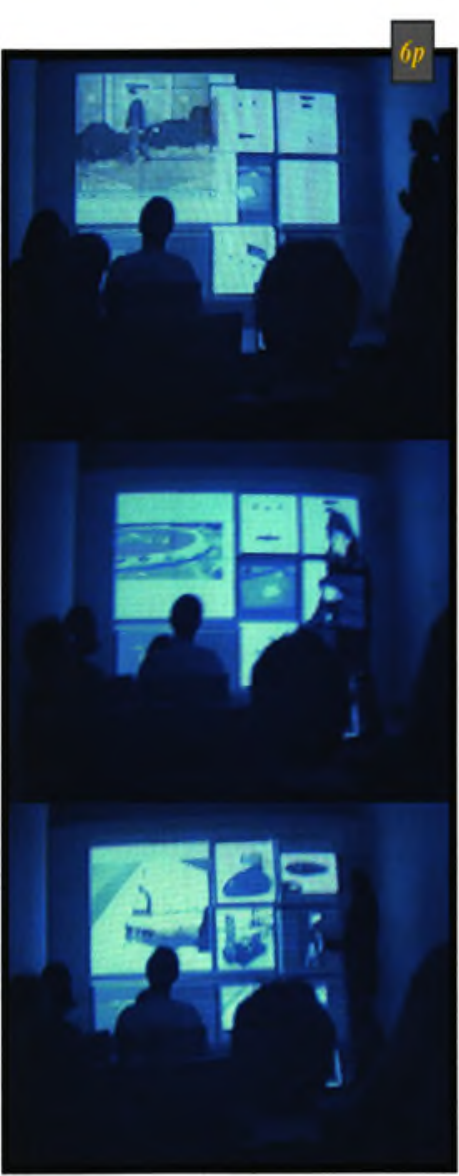

uals engaging in other activities within the park, meet for a pleasant social exchange. (Figure 6r1) Along this corridor, an open office space for a librarian, or mediator of information, is placed for convenient visitor access. A small office for the media technician and media storage is also situated along this ground floor passageway. Both technician and librarian monitor the central core of the Facility, which is the technology and server room. All wires and cables used for the transmission of data within the building, travel downward to this space. (Figure 6h) On the other side of this server room is the Village Meeting Room. This is the only room shared by the Village Council offices and the Information Facility. Therefore, this space becomes an interface, not only for community connections, but for bridging the old building with the new.

As visitors travel up to the next level, they are no longer influenced only by the ground level surroundings. Here, the visitor experiences views of the park as one entity. (figure $6 \mathrm{~s}$ ) The plan of the second level is demonstrated in terms of the parks interaction with the community. (Figure 6s1) Groups from the Village, as well as out of town visitors have the oppor. tunity to rent the $1000 \mathrm{sq}$. ft. meeting space, which encompasses most of this floor area. This media room is located on the northwest side of the building. Visitors benefit from views of the park's natural habitats when taking a break on the buildings southeast patio. 


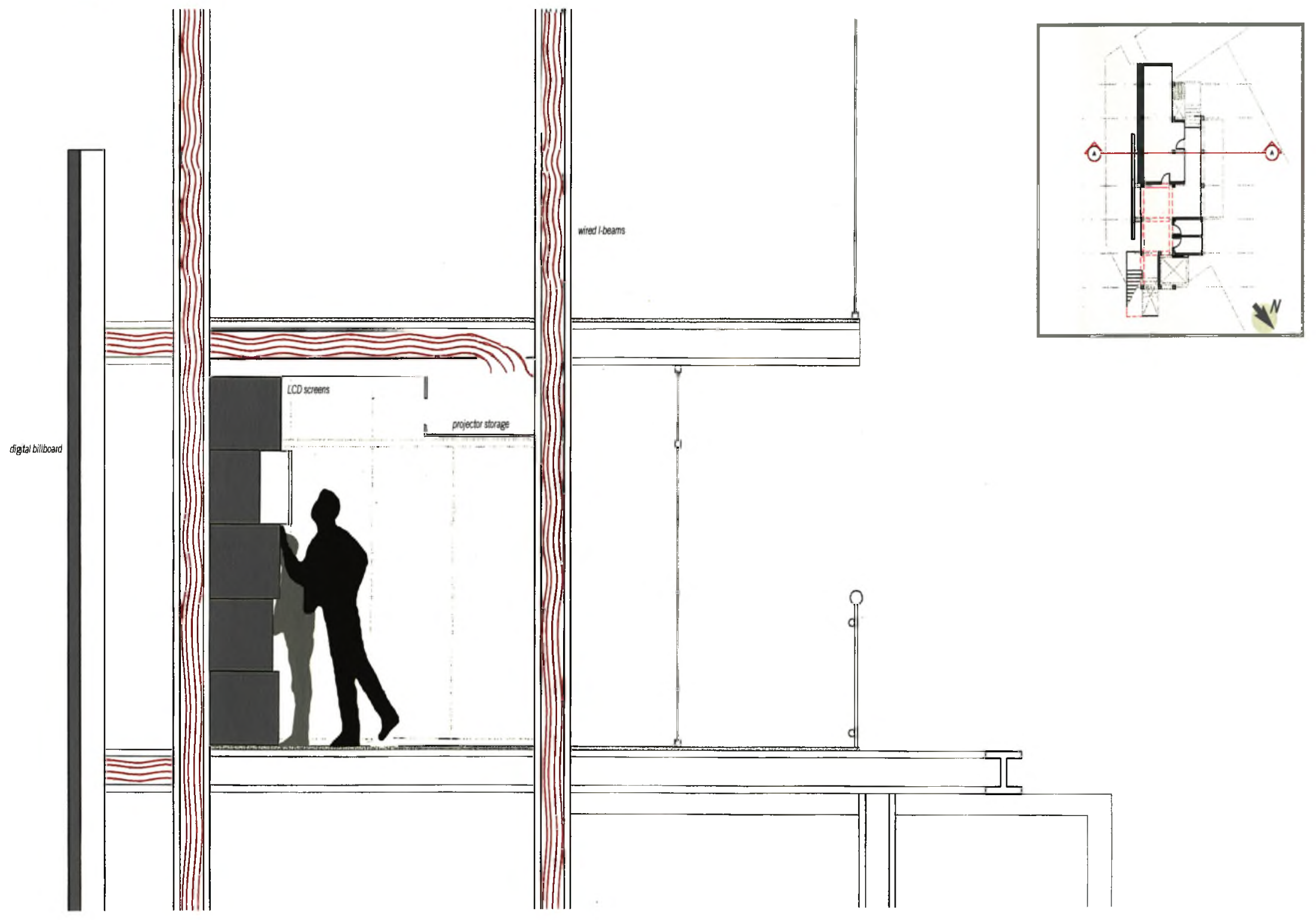



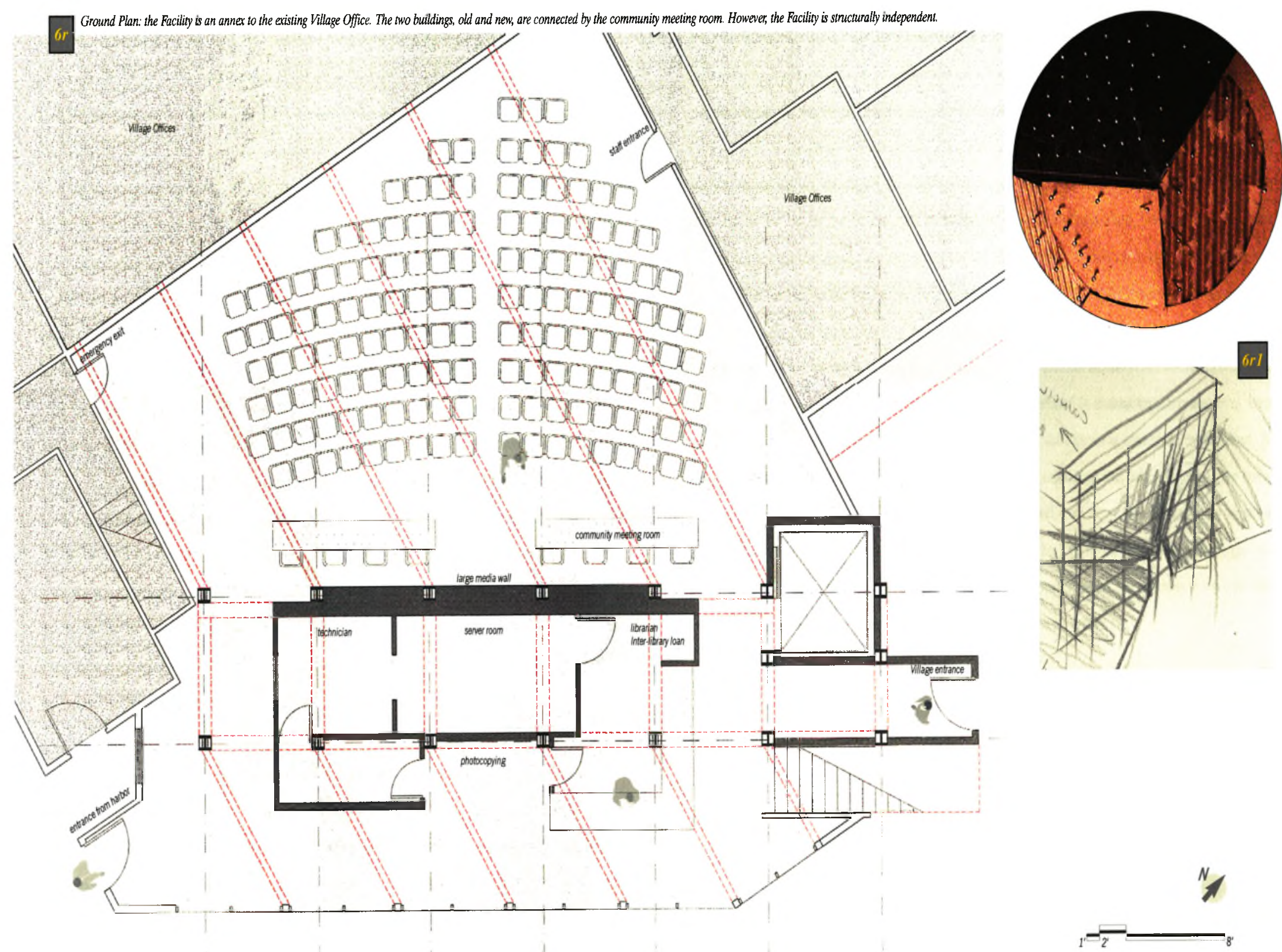
Visitors are transported beyond the Founder's Park experience as they climb to the third level. Elevated views and experiences contribute to the feeling of floating above the Village. As interaction at the community scale is dependent upon Route US1 and the connection of the four islands, "this central level acts as a connection between all the individuals of the community. (Figure 6t1) The visitors from the community meet through the design of group-size media spaces. (Figure 6t) Visitors are encouraged to access information for community meetings, school projects, personal research, etc... The media walls of the Facility are most frequently used on this level and best exemplified in Figure 6q. Social behavior also occurs on this floor due to the presence of the Center's restrooms, soda machines and exterior break areas.

The environmental variables previously discussed are less pronounced when arriving at the fourth level. At approxi. mately $60^{\prime}$ above sea-level, visitors are far removed from the activities below. Connections on this floor are privatized through the design of spaces for individual media interactions. (Figure $6 u$ ) Three $8^{\prime} \times 10^{\prime}$ rooms are designed with individual media walls proportional to the human body. Each room is docked along the corridor and projects outward with views towards the Bay. (Figure 6u1) The private 'docking experience' references the docking of boats in the harbor below. (Figure 6u2)

A spiritual experience emerges on the fifth and final floor of the building, as one climbs up towards the sky. Aside for the existence of solar panels, (Figure $6 v \& 6 \mathrm{v}$ ), the architecture of this level is lofty and left open to the sky. The experience here is less about the human body and more about the buildings connection with the universe. Information gathered and sent from within the Facility, transmits to it's next destination through radio waves. Satellites and other communication technologies are supported on this floor by a radio mast. (Figure 6v2) The Information Facility becomes an interface; an architectural entity, which stimulates dialogue between the Islamorada residents, the environmental context and the information world.

\subsection{Beyond Mediation}

Our relationships with technology have been considered indirect interactions and therefore, cold and alienating. In recent years computer technology has become more sensitive to the needs of the user. Despite improvements, digital infor. mation access is still otten limited to the confines of remote machines. Examination of radical experiments conducted by industrial designers and engineers at Cranbook, MIT and others, demonstrated how digital information will soon encompass our surroundings. Instead of interacting with keyboards and monitors, we will now be able to access informa- tion without limits from desks, floors, walls, and other surfaces of our defined environments. As a result, architects now share in the equation to design more humanized information access systems.

The problem of misinformation and lack of information access in Islamorada provided a unique opportunity to test the success of the technology-environment connection within the realm of architecture. A Digital Information Facility, where locals can access information in a non-jintimidating manner is designed, in order to bridge the gap between high technology and the informal Keys community. As the building complements it's surroundings, it thus becomes an interface. The Digital Information Facility for Islamorada expands upon traditional notions of interface design and includes a connec. tion between Islamorada residents and necessary technology and information. Ultimately, it connects the residents to the rest of the world. The Center is not a new invention, just a model re-packaged for the twenty-first century.

The importance of interfacing at many different scales became an essential element within the architectural design of the Facility. In fact, the building becomes a system of consecutive interfaces. By allowing the user to customize 'media walls' to meet organizational, functional, social and emotional needs, one's sensorial experiences are enhanced. The former indirect-remote interactions with technology are replaced by experiences that speak directly to the human condition. When all kinds of interactions within the Facility are considered, from the scale of the resident to the global, alienating technology is eliminated. The visitor's attention is focused back to his/her immediate surroundings. This ergonomic environment not only mediates, but actually encourages information access. The objectives of this thesis have been met. However, the dynamic role of interface in architecture is only in it's infancy. 
1. For a detailed discussion of the location see p. 20 .

2. For a detailed discussion of lighthouses see p. 23.

3. For a detailed discussion of radio antennas see p. 24.

4. For a detailed discussion of ecological concerns see p. 24

5. For a detailed discussion on sun exposure see p. 24.25

6. For a detailed discussion of this matter see p. 24.

7. For a detailed discussion on sun exposure see p. 24.25

8. For a detailed discussion of the MIT media surfaces see p. 17.19.

9. A representation of a media wall for the Center was designed and constructed for the final thesis defense presentation. See sample videoclips in Figure 6p. Author, Thesis Defense (Miami: Florida International University, collection of the author, presented on April 27, 2001), video recording.

10. For a detailed discussion of these variables see $5.5:$ scale in context, $p .25 .27$.

11. Plantation Key, Windley Key, Upper Matecumbe Key and Lower Matecumbe are the four istands that make up the Village of Islamorada.

12. More information about such communication technologies in relation to architecture is found in the authors, "Data

Communications in Communication Technology: with an assessment of Gustav Peichl's ORF Studios" (Miami: Florida Internationa University, research in Building Technologies, Fall 1999), 1.14. 

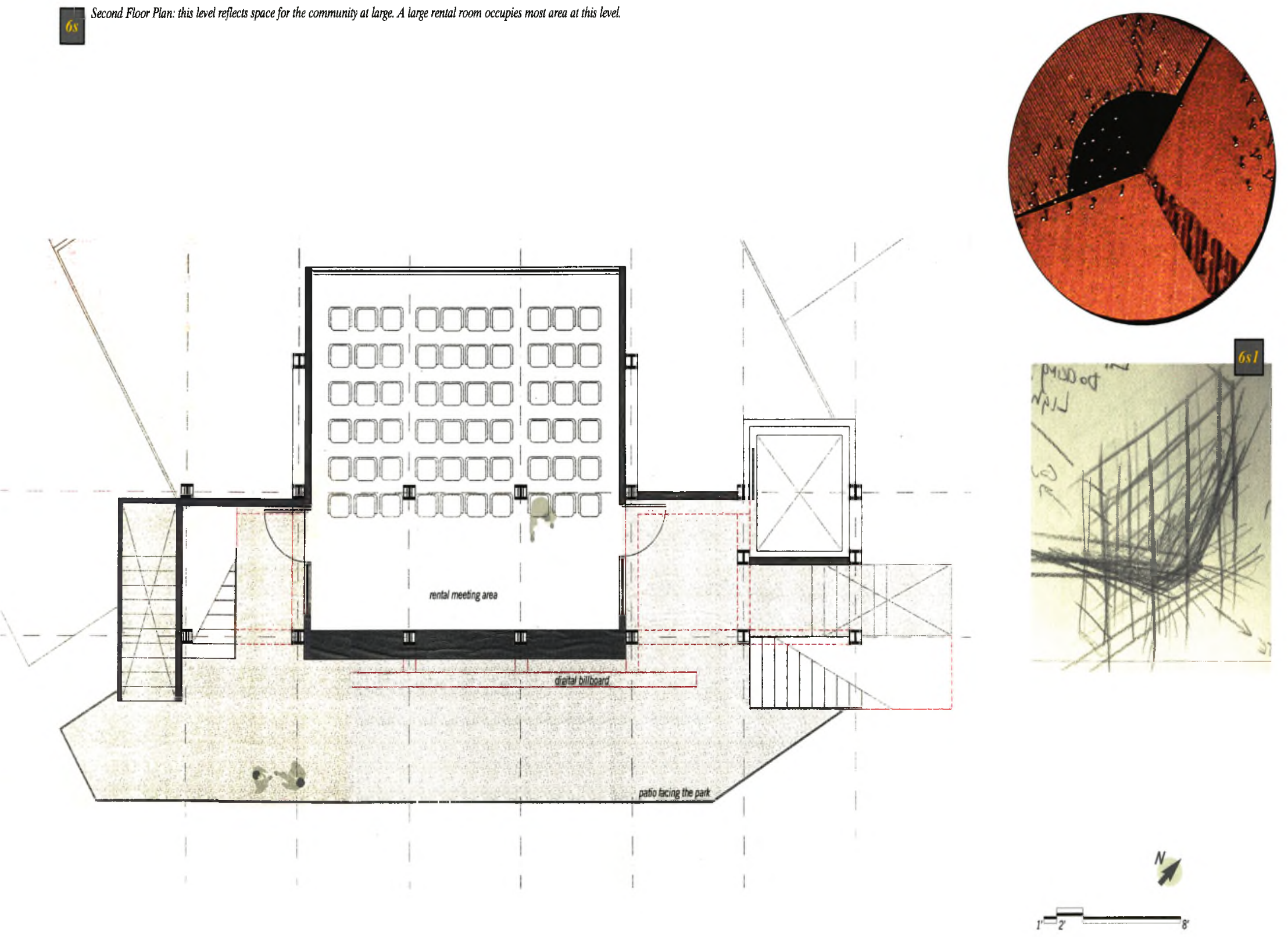
Third Floor Plan: this central level is the meeting grounds where all informal social interaction takes place.
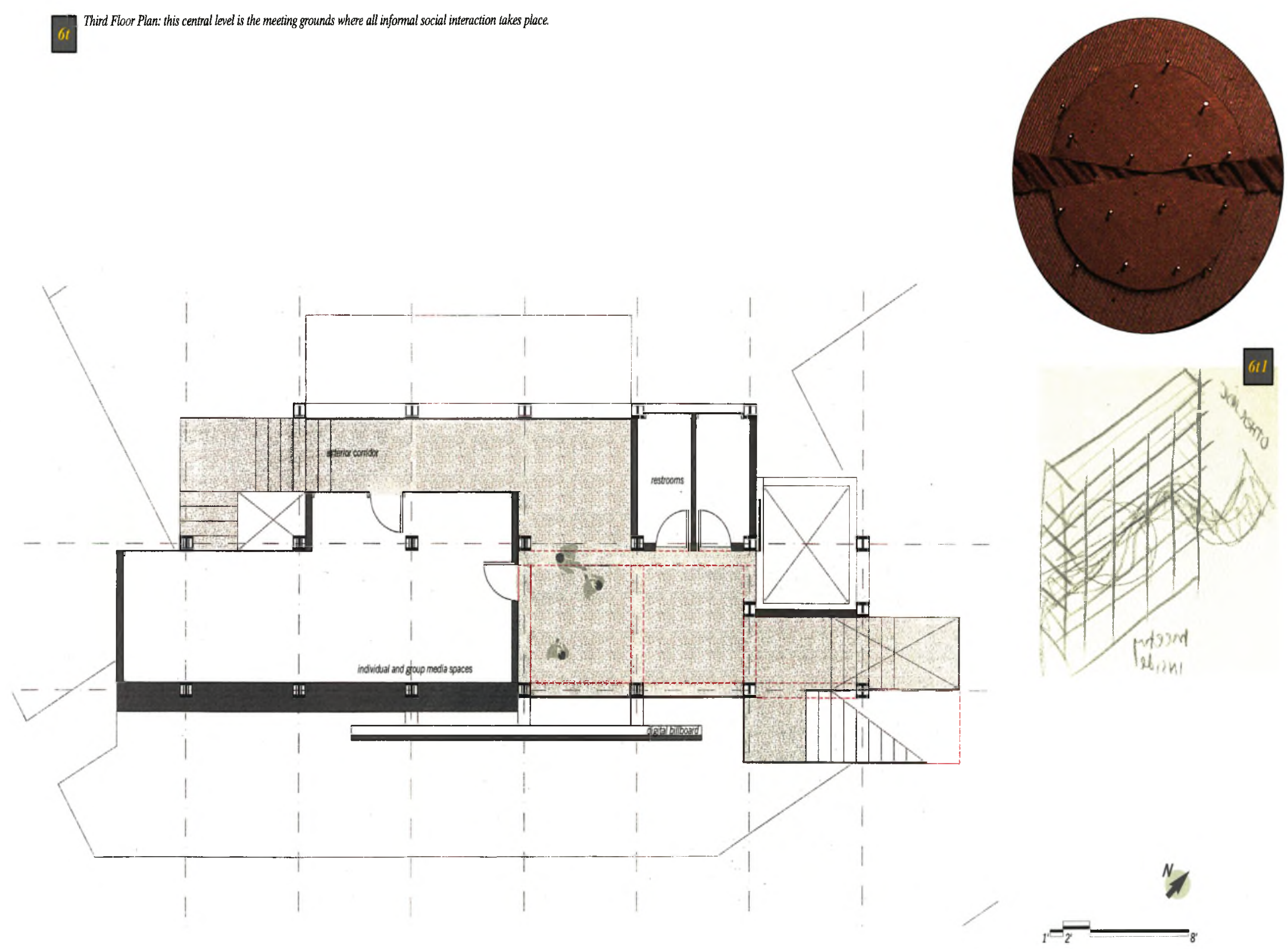

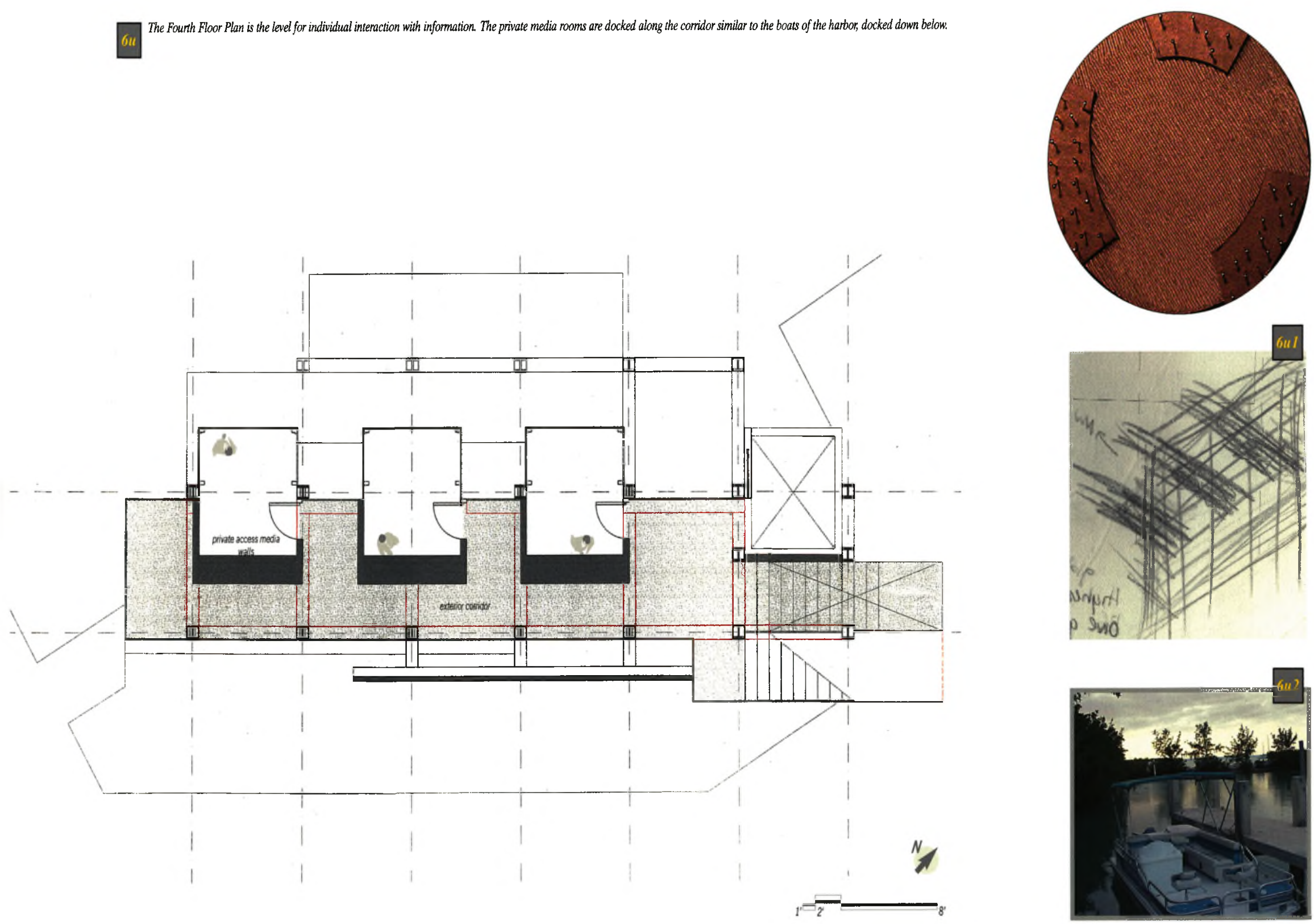

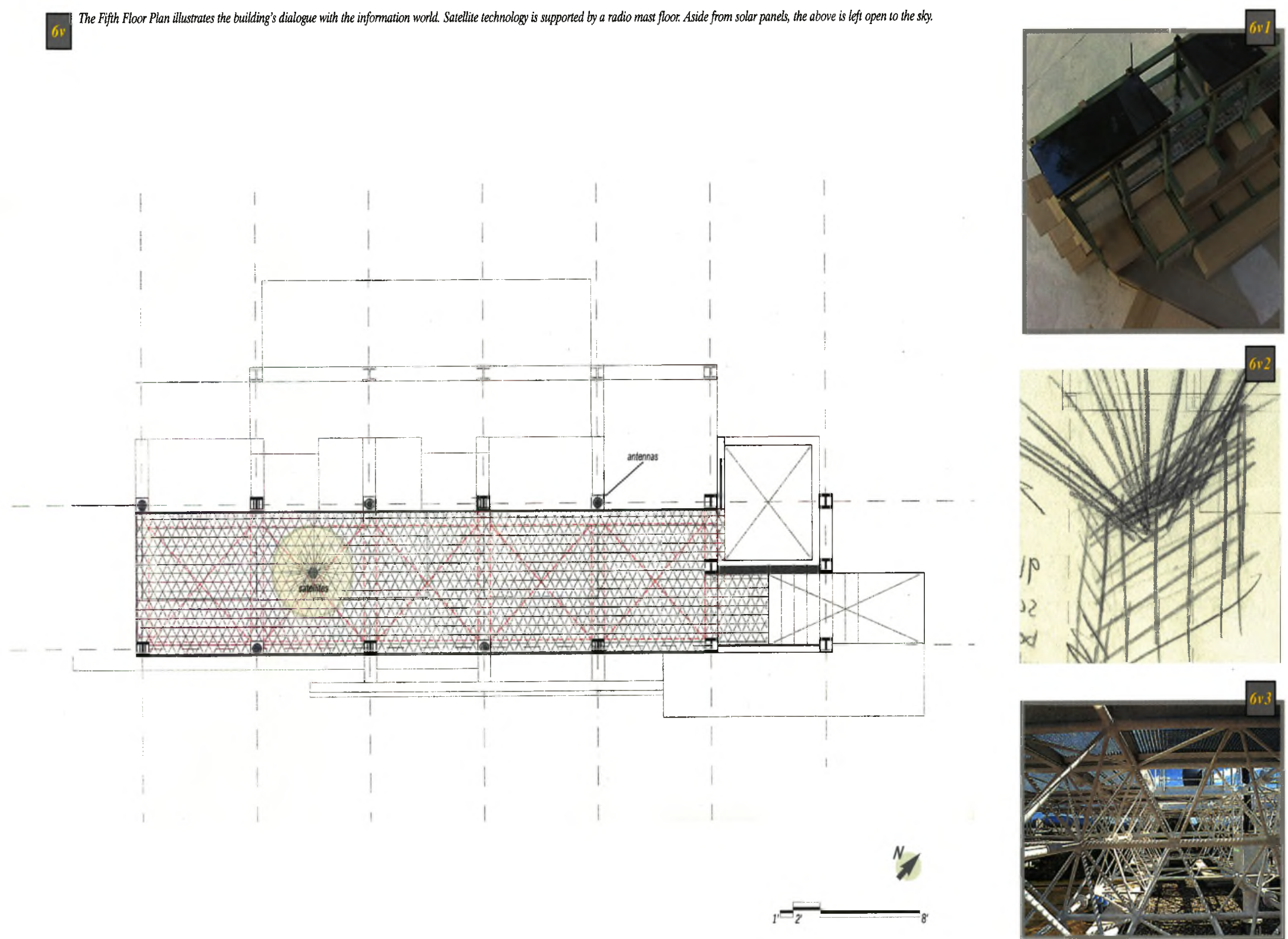


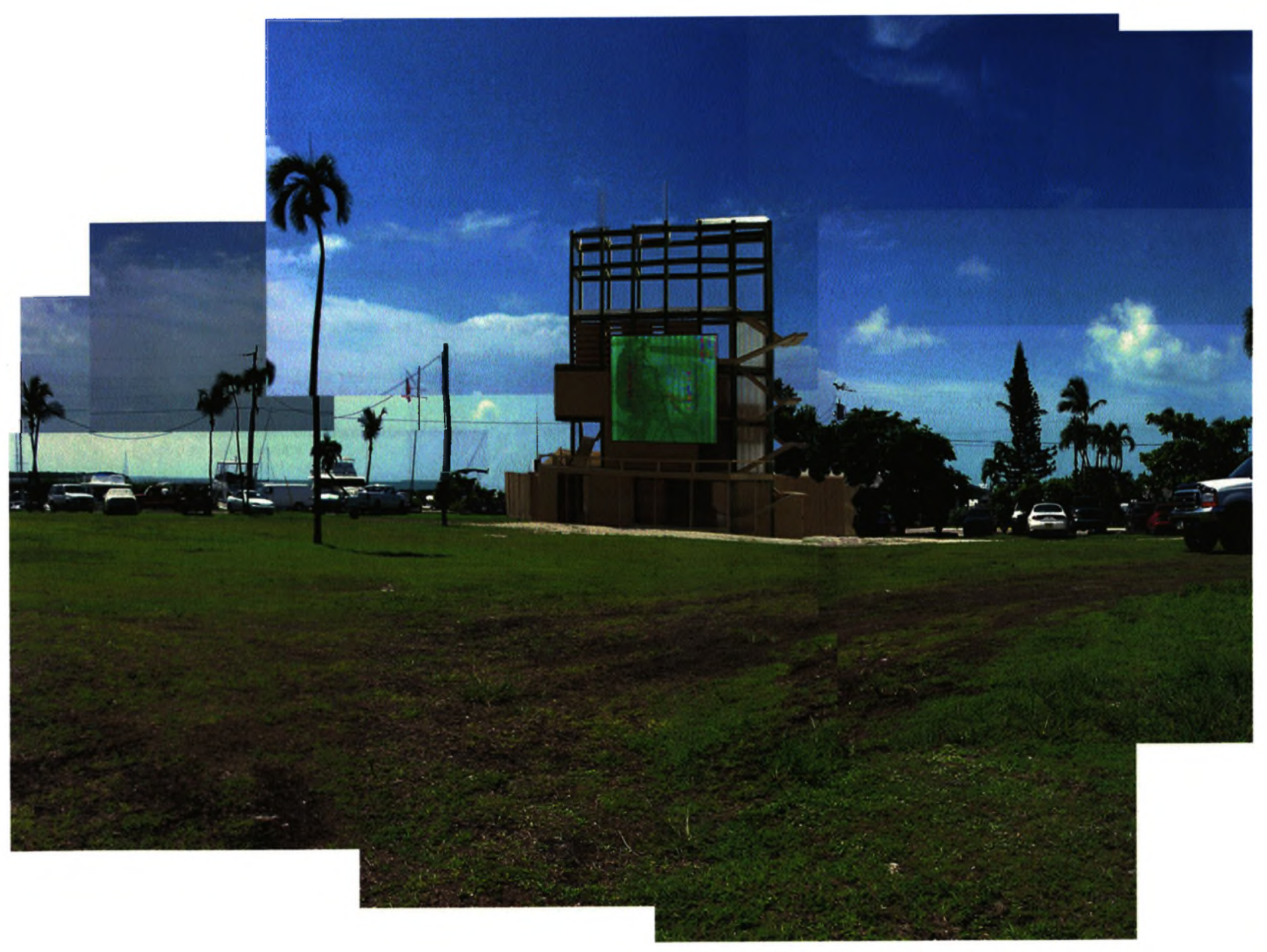




\section{SELECTED BIBLIOGRAPHY}

Aldersey-Williams, Hugh, ed. Cranbrook Design: The New Discourse. Essays by Roy Slade, Niels Difrient, Katherine and Michael McCoy, Hugh Aldersey.Williams, Darlice Bales, and Lorraine Wild. New York: Rizzoli, 1990.

"Object Culture." Blueprint, 49, July.August 1988, 38.39.

Barthes, Roland. Mythologies. Edited and translated by Annette Lavers. New York: Hill and Wang, 1972.

Brand, Stewart. The Media Lab: Inventing the Future at MIT. New York: Viking Penguin, Inc., 1987.

Brown, G.Z., and Mark Dekay. Sun, Wind \& Light: Architectural Design Strategies, 2d ed. New York: John Wiley \& Sons, Inc 200

Cantz, Hatie, ed. Connected Cities. Duisburg am Rhein: Exhibition at Wilhw/m Lembruck Musuem Duisburg, June 20 . August 1,1999 .

Clark, Robert.Judson, et al. Design in America: The Cranbrook Vision, 1925-1950. New York: Abrams, Detroit Institute of Arts and Metropolitan Museum of Art, 1983.

Cranbrook Academy of At: Academic Programs. Bloomfield Hills, Michigan: Cranbrook Academy of Art, 1998. Available from http://wWw.cranbrookart.edu/programs.html.

Cranbrook Academy of Art. Cranbrook: A Search for Form. Michigan: Signet Printing, 1982.

"3... Days at Cranbrook." Emigre Magazine, 19, 7.16.

Erikson, Annmarie and Grant Kester, eds. Cranbrook Academy of Art Graduate Studies Catalogue. Michigan: E \& G Prepress and Printing, 1998.

Eyster, Jeane and Irving. Islamorada and More. Marathon, Fl: Pigeon Key Foundation, 1997.

Feinberg, Linda. "Data Communications in Building Technology: with an assessment of Gustav Peichl's ORF Studios." Miami: Florida International University graduate class in Building Technologies, Fall 1999.

_ "Design Projects at the Cranbrook Academy of Art from 1987.1994 (During the McCoy Curriculum): An analysis of the interspaces between objects of technology and the human." Thesis research paper, Miami: Florida International University, December 2000.

Foster, Hal. The Anti Aesthetic: Essays on Postmodern Culture. Seattle, Washington: Bay Press, 1983.

Fredericksen, R., Pival P., and Suhr. "Technology Planning Program Draft for Nova Southeastern University Library and Technology Centers." Fort Lauderdale, Florida: Nova Southeastern University. March 29, 1999.

Gato, Jeanette, ed. The Monroe County Environmental Story. Big Pine Key, Florida: The Monroe County Environmental Education Task Force, 1991.

Greenaway, Peter, Schweeger, Elisabeth, et al. The Stairs: Aunich projection. London: M. Holberton, 1995.

Huff, Leif. "Form Follows Function... and then what?" M.A. Thesis, Cranbrook Academy of Art, May 9, 1994
Krohn, Lisa and Michael McCoy. "Beyond Beige: Interpretive Design for the Post-Industrial Age." Design Issues, 5, no. 2 (Spring 1989): 112.123

Laurel, Brenda. The Art of Human Computer Interface Design. Reading, Massachusetts: Addison-Wesley Publishing Company, Inc., 1990

Love, Dean. Lighthouses of the Florida Keys. Sarasota, Florida: Pineapple Press, 1998.

Lupton, Ellen. "The Academy of Deconstructed Design." Eye Magazine, 3, n0.3, Spring 1991, 44.63.

Lyotard, Jean Francois. Phenomenology. Translated by Brian Beakley. Albany: State University of New York Press, 1991

Margolin, Victor, et al. "Closing essay by Victor Margolin." Design Discourse. Chicago: University of Chicago Press, 1989

McCoy, Katherine and John David Rabinovitch. Future Wave: Japan Design. 30 min. New York: Cinema Guild, 1986 Videocasette.

McCoy, Katherine, "Back Talk: Katherine McCoy, Educator, Designer, Writer." Interview by Steven Heller. Print, 52, no.4 (July.August 1998): 38

_. Design in Michigan, 1967-1977. Detroit: Wayne State University Press, 1978.

Conversations in Design. prod. Claes Jonasson and College of Design at lowa State University, 20 min. New York: Insight Media, 1990. Videocasette.

McCoy, Michael. "The Post-Industrial Designer." Product Semantics '89: Proceedings from the Product Semantics ' 89 Conference in Helsinki, Finland, May 16.19, 1989, by the University of Industrial Arts. Helsinki: The Finnish Government Printing Centre, 1990. e:3.13.

Miro, Marsha. "Design as Discourse." Casabella. June 97, 38.47.

MIT Media Lab website. Cambridge, Ma.: Communications and Sponsor Relations [CASR], 2001. Database on-line Available from http://www.media.mit.edu/Information.

Noblet, Jocelyn de., ed. Industrial Design: Reflection of a Century. Paris: Imprimerie Clarc S.A., 1993.

Negroponte, Nicholas. The Architecture Machine. Massachusetts: MIT Press, 1970.

New Websters Dictionary and Thesaurus. Danbury, Ct: Lexicon Publications, Inc. 1993.

Omojola, O., Post, E.R., Hancher, M.D., et al. "An Installation of Interactive Furniture." Systems Journal: MIT Media Laboratory, 2d ed. 39, $3 \& 4(2000): 861$. Available online from $\mathrm{http}: / /$ www.research.ibm.com/journal/sj/393/part3/omojola.htm

OMA/LMN. "Seattle Public Library Proposal." Washington: Seattle Public Library, December, 1999. Available online from http://www.spl.org/lfa/central/oma/OMAbook1299/html.

Paradiso, J.A., Hsiao, K., Strickon, J., et al. "Sensor Systerms for Interactive Surfaces." Systems Journal: MIT Media Laboratory, 2d ed. 39, 3 \& 4 (2000): 892. Available online from http://www.research.ibm.com/journal/sj/393/part3/paradiso.htm 
Physics \& Media Group website. Cambridge, Ma.: Communications and Sponsor Relations [CASR], 2001. Database on-line. Available from http://gn.www.media.mit.edu/physics/purpose.html.

Rabinovitz, Robert. "Explorations and Projects in the Human Experience of Sensorial Phenomena." M.A. Thesis, Cranbrook Academy of Art, May 9, 1994.

Responsive Environments Group website. Cambridge, Ma.: Communications and Sponsor Relations [CASR], 2001. Database on.line. Available from http://gn.www.media.mit.edu/resenv/motto.html.

Riley, Terrance, ed. The Unprivate House. New York: The Musuem of Modern Art, July 1.0ctober 5, 1999

Saussure, Ferdinand de. Troisieme Cours de Linguistique Generale 1910-1911 (Third Course of Lectures on General Linguistics 1910-1911). Edited by Eisuke Komatsu. Translated by Roy Harris. Oxford, New York: Pergamon Press, 1993. ,

Slade, Roy, Katherine McCoy and Michael McCoy. Fifty Years of Cranbrook Design: A Culfural Presentation of the United States of America. Michigan: Cranbrook Academy of Art Museum, 1989

Slade, Roy, Gerhardt Knodel, Graham Marks, and Gary S. Griffin. The Cranbrook Tradition: Shared Boundaries. St. Louis: Craft Alliance, 1989.

Square One Research Pty Ltd. Square One. Nedlands, Australia: The School of Architecture and Fine Arts, The University of Western Australia, 2001. Database online. Available trom http://www.squ1.com.

Udagawa, Masamichi. "Untitled." M.A. Thesis, Cranbrook Acaderny of Art, May, 1990

Venturi, Robert and Denise Scott Brown. Learning from Las Vegas. New York: Museum of Modern Art: Doubleday, 1977

Viele, John. The Florida Keys: A History of The Pioneers. Sarasota, Fl: Pineapple Press, Inc. 1996
The following is a list of theses that were referenced for this study from the Cranbrook Academy of Art Library. Each thesis is listed in order of completion.

Harel, Dan. 1985

Gresham, David. 1986

Ferguson, Daniel. 1986

Eitelman, Greg. 1986

Shumacher, Sheri. 1986

Chung, Ronald. 1986

Fisher, Andrew. 1986

Tsai, Van Hong 1987

Carpenter, Pam. 1987

Teasdale, Jonathan. 1987

Montgomery, Paul, 1987

Cheng, Jin Dean. 1987

Ah, Julie Sook. 1987

Hili. Jim. 1987

Goralski, William. 1988

Krayer, Kenneth. 1988

Krohn, Lisa. 1988

Scott, Michael. 1988

Stefura, Marcia. 1988

Wang, Chiang Lang. 1988

Deines, Kelly. 1989

Kritaman, Brian. 1989

Lasch, Carol. 1989

Lawrence, Tod Christopher, 1989

Lewis, Charles Richar, Jr. 1989

McAdams, Kendall. 1990

Prange, Laura. 1990

White, Philip Byron. 1990

Wurx, William. 1990

Williams, Eric. 1991

Davidson, John. 1991

Ito. Miko. 199]

Fitzgerald. Kevin. 1991

Udagawa, Musumeci. 1991

Langhoff, Lisa. 1991

Andrews, Craig. 1992

Brog, Wendy Sue. 1992

Carr, Ronald. 1992

Rabinovitz, Robert. 1992

Shachat, Abigail. 1992

Oliphant, Thomas. 1993

Scott, George Winfield III. 1993

Dougherty, Michael. 1994

Gallagher, Kevin. 1994

Huff, Leif. 1994

Johnson, Callie. 1994

Shields, David. 1994 